Gerión. Revista de Historia Antigua

ISSN: 0213-0181

http://dx.doi.org/10.5209/geri.71944

\title{
Los manuscritos de los médicos directores de balnearios de la biblioteca de la Facultad de Medicina de la Universidad Complutense de Madrid: documentación sobre balnearios romanos ${ }^{1}$
}

\author{
Gonzalo Matilla Séiquer ${ }^{2}$
}

Recibido: 12 de octubre de 2019 / Aceptado: 22 de junio de 2020

Resumen. Se hace un recorrido por la colección de manuscritos referentes a los balnearios españoles que se conserva en la biblioteca de la Facultad de Medicina de la Universidad Complutense de Madrid. Se refleja la legislación que da origen a los manuscritos y que especifica su contenido. También los problemas de custodia y conservación que han provocado que hoy sólo exista el $5 \%$ de los que se escribieron. Por último, se analiza el contenido de los textos y sus posibilidades para utilizarlos en el estudio del mundo antiguo a partir de los datos arqueológicos, numismáticos, epigráficos, gráficos y de medicina previa al siglo XIX.

Palabras clave: termalismo antiguo; epigrafía; numismática; arqueología; agua minero-medicinal.

\section{[en] The Manuscripts of the Medical Directors of Spas of the Library of the Faculty of Medicine of the Complutense University of Madrid: Documentation on Roman Spas}

\begin{abstract}
A survey is made on the collection of manuscripts referring to Spanish healing spas preserved in the library of the Faculty of Medicine of the Complutense University of Madrid. The legislation that gives rise to the manuscripts and specifies their content is reflected. Also the problems of custody and conservation that have caused that today there is only $5 \%$ of those that were written. Finally, the contents of the texts and their possibilities for use in the study of the ancient world are analyzed based on archaeological, numismatic, epigraphic, graphic and medical data.
\end{abstract}

Keywords: Ancient Thermalism; Epigraphy; Numismatics; Archaeology; Mineral Water.

Sumario. 1. Introducción. 2. El origen de los manuscritos. 3. Los manuscritos conservados. 4. La custodia de los manuscritos: del Ministerio de la Gobernación a la Facultad de Medicina de la Universidad Complutense. 5. Los manuscritos y la Historia Antigua: de la Arqueología a la Epigrafía. 5.1. La veracidad de la información de los manuscritos. 5.2. El contenido de los manuscritos. 5.3. La información arqueológica. 5.4. La información numismática. 5.5. La información epigráfica. 5.6. La información gráfica. 5.7. Otras informaciones. 6. Conclusión. 7. Referencias bibliográficas.

DOCEMUS-CM. Ref. S2015-HUM3377, de la Comunidad de Madrid/Fondo Social Europeo.

2 Universidad de Murcia - CEPOAT.

E-mail: gmatilla@um.es

ORCID: 0000-0003-4258-8175 
Cómo citar: Matilla Séiquer, G. (2020): Los manuscritos de los médicos directores de balnearios de la Facultad de Medicina de la Universidad Complutense de Madrid: documentación sobre balnearios romanos, en Gerión 38/2, 459-487.

\section{Introducción}

Con independencia de que las aguas minero-medicinales pudieran haber sido usadas como recurso médico desde la prehistoria y con certeza absoluta de ese uso desde el mundo griego y el protohistórico de toda la cuenca del Mediterráneo, ${ }^{3}$ el verdadero auge del termalismo como fenómeno médico de masas se lo debemos a los romanos.

La importancia del termalismo romano ha quedado suficientemente explicada en la literatura científica. ${ }^{4}$ Baste decir a modo de resumen que autores literarios como Marcial y Propercio, científicos como Vitrubio y Séneca o médicos como Celso y Oribasio se han ocupado de ello en mayor o menor grado. Un buen ejemplo de su significado como punto de referencia en el mundo romano lo encontramos en la Tabula Peutingeriana. ${ }^{5}$ El reflejo de este interés por las surgencias medicinales lo vemos en los restos conservados de muchas de ellas. Es suficiente con citar unas pocas: Fortuna (España), Chaves-Aquae Flaviae (Portugal), Amélie-les-BainsAquae Calidae (Francia), Bath-Aquae Sullis (Inglaterra), Aquisgrán-Aquae Granni (Alemania), Montegrotto Terme-Aquae Patavinae (Italia), Hamat Gader (Israel) o Hammam es-Salihine (Argelia).

Se han establecido cinco categorías de balnearios romanos en función de la obra realizada en torno a las surgencias y, por lo tanto, de la afluencia de bañistas a los mismos. Los que estarían en la parte alta de la escala serían los que llegaban a recibir usuarios de diferentes provincias, mientras que en la parte baja estarían los que sólo tenían un uso local y presentaban nulas o escasas infraestructuras. ${ }^{6}$ Con independencia de su mayor o menor trascendencia en ámbitos inmediatos o alejados, las aguas de todos ellos tenían en común que eran medicinales y por lo tanto podían curar, pero siempre por la intermediación de una divinidad asociada o residente en las aguas. ${ }^{7}$

Merced a ese carácter sacro de las curaciones realizadas en estos lugares, entre otros elementos, son frecuentes las inscripciones votivas ${ }^{8}$ y las monedas utilizadas a veces como óbolos previos a la promesa del enfermo o como ofrenda votiva posterior a la curación. ${ }^{9}$

Tras el mundo romano, sin que nunca se perdiera del todo la tradición de tomar las aguas en los entornos inmediatos a las surgencias, la repercusión social y médica

Oró 1996, 24-26.

4 Hay mucha bibliografía al respecto. Basten estas obras de conjunto para ilustrar la cuestión: Peréx - Bazzana 1992; Peréx 1997; Guérin-Beauvois - Martin 2007; Matilla - González-Soutelo 2017a.

Peréx - Rodríguez 2011, 153-170; Morandini 2013, 273-287.

Matilla - González-Soutelo 2017b, 49-51.

Díez de Velasco 1998.

Díez de Velasco 1998; Redentor 2017; Andreu 2018.

Abad 1992; Arias - Matilla 2011. 
de los baños se diluyó. Habrá que esperar a la publicación, en 1697, del Espejo cristalino de las aguas de España de Alfonso Limón Montero para que comience de nuevo el camino de la recuperación del uso de las aguas minero-medicinales. Éste concluirá a principios del siglo XIX con la eclosión de un termalismo universal desde los ámbitos médico y social que, con altibajos, perdura hasta el día de hoy.

En esta primera obra, cuando el autor tiene datos acerca de la antigüedad de los baños, sean estos reales o falsos, lo refleja, como se puede comprobar en los casos de Sacedón, Alhama de Aragón o Ledesma, recogiendo incluso una inscripción romana atribuida a la Fuente de Piedra o de Antequera. ${ }^{10}$ Por otra parte, escribe un pequeño capítulo: "De los baños de los antiguos y su uso" "11 que es una verdadera premonición del interés que a lo largo de los siglos XVIII y XIX va a suscitar el posible origen romano de determinados balnearios.

A lo largo del siglo XVIII hay múltiples publicaciones sobre aguas mineromedicinales en las que se insiste en la antigüedad del uso de tales aguas y en las que, de forma general, los datos concretos sobre la romanidad de las instalaciones quedan reducidos a la recogida de la epigrafía asociada a los nacimientos. En su mayoría se trata de monografías acerca de baños concretos, como por ejemplo Luz de la verdad y extinción de preocupaciones, tratado de las aguas thermales de la villa de Caldes de Monbuy del principado de Cataluña, publicada en 1790 por Juan y Salvador Broquetas, pero también hay obras generales. En este sentido hay que destacar el esfuerzo enciclopédico realizado por Pedro Gómez de Bedoya, que se propuso publicar las fuentes y baños más notables de España en seis volúmenes de los cuales solo vieron la luz los dos primeros, en 1764 y 1765, y que, bajo el título de Historia universal de las fuentes minerales de España, comprendían hasta la letra "F". En su obra abundan las referencias a vestigios romanos en los balnearios, haciendo referencia a yacimientos, ${ }^{12}$ restos arquitectónicos, ${ }^{13}$ monedas ${ }^{14} \mathrm{y}$ en especial a inscripciones, de las que recoge tanto el texto como la forma del soporte. ${ }^{15}$

A lo largo de toda esta centuria no sólo el interés médico por los baños medicinales fue en aumento, sino que empezaron a ser concurridos por muchos enfermos que veían en ellos la única solución posible a dolencias por las que habían sido desahuciados. Si la obra de Ayala de 1777 sobre los baños de Archena (Thermae Archenicae sive De balneis ad Archenam in agro murcitano: Carmen) no es una hipérbole erudita sobre las propiedades del manantial y está reflejando la consideración social hacia el agua de Archena, nos encontramos con la creencia de que los baños más que curativos son milagrosos. Habla de tres casos: el de una niña en estado vegetativo, el de un anciano completamente llagado y ulcerado y el de una prostituta con sífilis que tras entrar en la piscina se curan de forma espontánea. ${ }^{16}$

No es de extrañar que desde el gobierno se quisiera controlar el uso de este recurso médico para evitar que fuera un foco de infecciones. A esto hay que añadir el interés de la Corona por este tipo de establecimientos y su costumbre en el uso de este medio

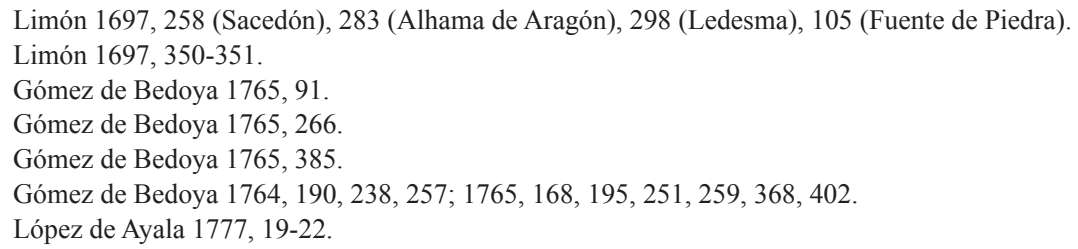


para buscar solución a las más variadas dolencias. El precedente hay que situarlo en la época de Carlos III con la creación del Balneario Real de Trillo, ${ }^{17}$ continuando con la protección por Fernando VI de los baños de Arnedillo, cuyas aguas habían curado a la reina, y que pasaron a denominarse Reales Baños de Arnedillo, ${ }^{18}$ siendo también visitados por Fernando VII. ${ }^{19} \mathrm{El}$ infante D. Antonio, hijo de Carlos III, promocionó los baños de Sacedón que, a partir de las obras realizadas en 1818 por la Corona, pasaron a denominarse Real Sitio de La Isabela. ${ }^{20}$ Por otra parte, es de sobra conocida la relación de Fernando VII con Solán de Cabras, donde acudió en 1826 con la reina en la esperanza de que las aguas curaran la supuesta esterilidad de María Josefa de Sajonia. $^{21}$

\section{El origen de los manuscritos}

De esta manera, la unión de la necesidad de control médico y la buena acogida de las aguas medicinales en la Corte, propiciaron que bajo el reinado de Fernando VII se aprobara el Real decreto de 29 de junio de 1816 "resolviendo que en cada uno de los baños mas acreditados del reino se establezca un profesor de suficientes conocimientos de las virtudes de sus aguas, y de la parte médica necesaria". ${ }^{22}$

A este primer decreto siguieron otros para regular tanto el sistema de acceso al cuerpo de médicos de baños como el funcionamiento de los propios establecimientos. ${ }^{23}$ Hay que destacar la publicación del primer reglamento extenso en mayo de 1817 que titulado: Reglamento que á propuesta de la Real Junta superior gubernativa de Medicina manda S. M. observar para la inspección, gobierno y uso de todas las aguas y baños minerales de España, especifica en su capítulo II, artículo 10:

Los médicos directores de aguas minerales anotarán con el cuidado y exactitud posibles cuantas mutaciones presenten el termómetro y el barómetro, é igualmente el influjo que estas manifiesten en los enfermos concurrentes que toman aquellas: formarán la topografía de sus puntos respectivos, y harán el examen físico y químico de las aguas, la historia natural y médica del parage que esté á su cargo; y al cabo de dos años de la provincia á que cada agua mineral corresponda. ${ }^{24}$

El artículo 17 habla de la obligación de remitir la memoria durante el mes de diciembre siguiente a la temporada de baños al Secretario de la Inspección General de Aguas Minerales en la que además se debe incluir el estado de las instalaciones, con las mejoras tanto realizadas como previstas. ${ }^{25}$

A lo largo del siglo XIX se hicieron nuevos reglamentos. El de 1828 no cambia nada en lo sustancial de las memorias, excepto la prohibición a los facultativos de

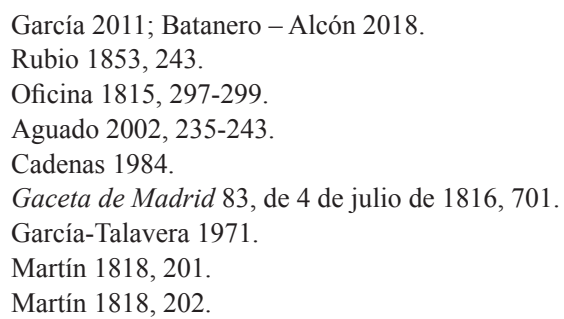


publicar las memorias anuales, cuya propiedad se reserva la Inspección General de Balnearios. $^{26}$

El reglamento de 1834 indica que los balnearios dejan de depender del Ministerio de Gracia y Justicia y pasan a subordinarse al recién creado Ministerio de Fomento, lo que tendrá repercusión en la posterior conservación de las memorias manuscritas.

Un nuevo reglamento se aprueba en los últimos momentos de Isabel II, el 11 de marzo de $1868 .{ }^{27}$ Las novedades respecto a las memorias son que cada tres años se redactará "una extensa Memoria en que se presente el estudio físico-médico y médico-topográfico de las aguas" 28 y que éstas, que deberán ser entregadas a la Dirección General de Beneficencia y Sanidad, se dividirán en tres partes:

La primera estará consagrada á la descripción de las fuentes, indicando el pueblo, jurisdicción, partido y provincia á que corresponden; describiendo asimismo detalladamente el establecimiento mineral, con el número de pilas, gabinetes, piscinas, estanques, baños de vapor, aparatos de chorro, mejoras realizadas ó proyectadas, topografía de los alrededores, distracciones propias de la comarca, alimentación, monumentos, curiosidades y paseos de las inmediaciones; distancia desde la capital y desde el pueblo más próximo al establecimiento y medios de comunicación hasta el mismo desde Madrid.

La segunda estará dedicada al estudio de las aguas, indicando su uso y el numero de las fuentes, las cualidades fisicoquímicas de aquellas, su temperatura respectiva, no solo durante la temporada oficial, sino además en los primeros dias de Marzo, Junio, Setiembre y Diciembre, para saber á qué atenerse sobre cada estación del año; la acción que hayan ejercido sobre personas que disfrutasen de buena salud y sobre enfermos según que se hayan administrado en bebida, baños, chorros, inhalación, pediluvios etc.; en qué casos el tratamiento da resultados más notables, haciendo constar si ha habido variación de temperatura, de principios minerales, de propiedades terapéuticas en alguna fuente; época y estación en que ha tenido lugar, y si es posible, en virtud de qué influencia; la naturaleza del terreno de que se creen procedentes las aguas, y si algún trabajo ó perforación subterránea ha alterado sus propiedades ó aumentado ó disminuido su caudal.

La tercera tratará de la constitución médica del país antes y durante la temporada de las aguas, $\mathrm{y}$ de las endemias de la provincia, como igualmente de las epidemias si alguna hubiere habido en ella. ${ }^{29}$

Se ordena también la elaboración por parte de los médicos de tres libros que han de permanecer en el establecimiento donde conste en el primero la historia del balneario, en el segundo la legislación referida a aguas minero-medicinales y en el tercero las memorias anuales o trienales originales. ${ }^{30}$ La obligación de que esa documentación permaneciera en las instalaciones termales ha provocado que estos manuscritos no se hayan conservado en casi ningún caso.

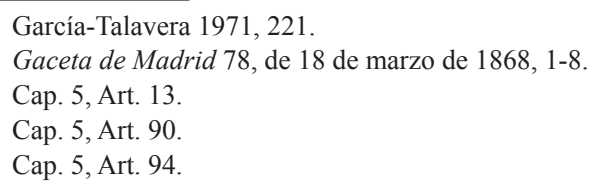


En 1871, con Amadeo I, el nuevo reglamento no presenta cambios sustanciales respecto a las memorias ${ }^{31}$ y en 1874 el reglamento bajo la regencia de Serrano, luego ratificado por Alfonso XII, introduce como novedad la obligación de adjuntar a la memoria que ha de remitirse al Consejo de Sanidad un:

(...) cuadro estadístico médico con distinción de la clase de padecimientos tratados y de los efectos comprobados, y otro del número de enfermos en la temporada, expresando la provincia de donde proceden, los que pertenecen á la clase acomodada y los que son pobres y soldados. ${ }^{32}$

A partir de este momento no habrá cambios en lo que queda de siglo XIX y los ulteriores ya no afectarán a las memorias que dejan de entregarse a principios del siglo XX.

\section{Los manuscritos conservados}

La primera relación de baños que han de tener médico director se publica el 15 de mayo de $1817^{33}$ y comprende 30 establecimientos: Trillo en Guadalajara, El Molar en Madrid, Alcantud y Solán de Cabras en Cuenca, Puertollano en Ciudad Real, Ledesma en Salamanca, Arnedillo en Rioja, Quinto, Alhama de Aragón y Tiermas en Zaragoza, Panticosa en Huesca, Caldas de Oviedo en Asturias, Marmolejo y La Aliseda en Jaén, Graena en Granada, Alhama de Almería en Almería, Ardales en Málaga, Bornos en Cádiz, Caldas de Montbuy y Caldetas (Titus) en Barcelona, Alange y Fuente del Oro (Castañar de Ibor) en Cáceres, Cortegada en Orense, Caldas de Reyes, Cuntis y Caldelas de Tuy en Pontevedra, Fitero y Velascoain (Belascoain) en Navarra, Busot en Alicante y Archena en Murcia. Alguno de ellos no tenía mucho sentido que estuviera en esta lista como es el caso de la Fuente del Oro de muy corta trayectoria en su repercusión nacional y que solo se explica por el uso que hacía la familia real de sus aguas, que eran llevadas desde la surgencia a la Corte, ${ }^{34}$ pero los demás estuvieron funcionando durante todo el siglo XIX y la mayoría sigue en activo en el XX. ${ }^{35}$

Sin tener en cuenta todos los balnearios que llegaron a tener médico director y que ascendieron al número de $203^{36}$ y considerando 29 establecimientos originales (con la exclusión de Fuente del Oro y la inclusión de Fitero Nuevo en 1846), la producción de memorias manuscritas anuales de los mismos entre 1816 y la fecha de la última memoria conservada de cada uno de ellos debería ascender a 2382. ${ }^{37}$ Sin embargo, en la biblioteca de la Facultad de Medicina de la Universidad Complutense para este periodo y de estos balnearios se custodian un total de 939 manuscritos ${ }^{38}$ que

\footnotetext{
Gaceta de Madrid 276, de 3 de octubre de 1871, 29-34.

Gaceta de Madrid 135, de 15 de mayo de 1874, 414-417. Art. 56. 9.a.

Gaceta de Madrid 58, de 15 de mayo de 1817, 502-503: "Oposiciones á plazas de médicos de aguas minerales". Alegre 1984, 5-7.

Maraver - Armijo 2010.

Incluido en ultramar el de San Diego de los Baños en Cuba. Maraver 1997, 46; Méndez 2008, XXVII-XXX.

Sin tener en cuenta las memorias trienales, las quinquenales y las que habían de permanecer en custodia de los establecimientos balnearios.

38 Respetando los criterios del catálogo de Méndez Aparicio se han incluido en este número los 16 trabajos impresos que corresponden a estos balnearios.
} 
corresponden en realidad a 774 memorias diferentes, ya que hay 4 que son copia y 123 que atañen a diferentes ejercicios de oposición para conseguir plaza de médico director. Además, otros 38 manuscritos responden a otras características diferentes a las memorias anuales, de los que el grupo más homogéneo, fechado entre 1844 y 1845 , es la respuesta a un cuestionario enviado a todos los balnearios por la comisión encargada de redactar el "manual de aguas minerales del reyno". ${ }^{39}$ Otro tipo de documentos conciernen a descripciones de particulares, analíticas, informes de los propietarios de establecimientos, etc. (véase Tabla 1).

Un simple cálculo deja patente que con 203 balnearios oficiales en funcionamiento el número de memorias manuscritas tuvo que superar las 15.000, por lo que lo conservado está en torno al 5\% de la producción total.

Hay que destacar también que en la mayoría de los casos los documentos son de la segunda mitad del siglo XIX, habiéndose perdido casi en su totalidad los manuscritos fechados entre 1817 y el comienzo de los años 40 . Se trata de una época en la que se hacen los primeros cambios en las antiguas casas de baños, comenzando un proceso de modernización y de adecuación a la nueva realidad sanitaria de España; por lo tanto, es el momento en que se describen las antiguas instalaciones, muchas de las cuales deberían ser las mismas infraestructuras construidas por los romanos ${ }^{40} \mathrm{y}$ en el que se hacen las primeras remociones generalizadas de tierra que podrían haber producido hallazgos epigráficos, numismáticos o arqueológicos en general.

Es cierto, por otra parte, que el segundo gran impulso que reciben los balnearios para su modernización es consecuencia directa de la inversión privada que entra en estos lugares merced a las diferentes desamortizaciones, entre la que habría que destacar la de Madoz que fue la que enajenó la mayoría de los balnearios.

\section{La custodia de los manuscritos: del Ministerio de la Gobernación a la Facultad de Medicina de la Universidad Complutense}

Hasta 1834 los balnearios dependen del Ministerio de Gracia y Justicia, fecha en que pasan a la jurisdicción del Ministerio de Fomento, aunque hasta 1851, como mínimo, los manuscritos eran remitidos al Ministerio de la Gobernación desde donde se enviaban al archivo de la Junta Superior Gubernativa de Medicina y Cirugía donde al parecer dormían el sueño de los justos mientras se prohibía a los facultativos de los diferentes baños que pudieran publicar sus memorias. El motivo es que la Junta tenía la intención de publicar una "Noticia General" de las aguas minero-medicinales en España. ${ }^{41}$

En 1840 Pedro María Rubio, desde su puesto al frente del despacho de negocios médicos en la secretaría de la Dirección General de Estudios, pretende afrontar la tarea de revisar las memorias archivadas para la publicación de una obra general acerca de los balnearios españoles y hasta donde sabemos es el primero en hacerlo desde 1817. Tras la primera revisión se da cuenta de que la falta de sistematización de las mismas dificulta la toma de datos, por lo que hace borrón y cuenta nueva y

Las fórmulas utilizadas difieren ligeramente, refiriéndose en algunos casos a España y en otros a la Península.

40 Como queda patente en balnearios como el de Zújar, donde las primeras informaciones describen un edificio y una piscina que después se pudo comprobar que eran romanos. Díez de Velasco 1992, 396-398.

41 Rubio 1853, IX. 
envía a los directores médicos una circular con un cuestionario que será la base de su obra. ${ }^{42}$

El Tratado completo de las fuentes minerales de España de Rubio tardó en ver la luz. No será hasta 1853 en que la obra esté concluida utilizándose para su elaboración, además de los cuestionarios referidos, las memorias de los años 1847 a 1851, todavía no elaboradas de forma ordenada y con un sistema semejante, como ocurrirá a partir del reglamento de 1868 , pero más asequibles de manejar por su reducido número y más interesantes desde el punto de vista médico pues la disciplina de la balneoterapia ya está consolidada.

En todo caso parece ser que los manuscritos hasta 1851 se conservaban sin mayores problemas a pesar de los diferentes cambios de dependencia de los balnearios oficiales.

En función de los datos obtenidos Rubio ofrece un listado que llama "Baños minerales de España de cuya antigüedad tengo noticia". En éste distingue entre los que están "en uso durante la dominación romana" y "durante la dominación sarracena". Entre los primeros cita: Alange, Alhama de Aragón, Alhama de Granada, Alhama de Murcia, Archena, Baños de Montemayor, Bellús, Busot, Buyeres de Nava, Caldas de Cuntis, Caldas de Estrac, Caldas de Malavella, Caldas de Montbuy, Caldas de Reyes, Carballo, Carratraca, Córcoles, Horcajo de Lucena, Ledesma, Lugo, Molgas, Orense, Sacedón y Tiermas; y entre los segundos, tras advertir que muchos de los romanos seguían en uso en época medieval, cita Alhama de Granada, Sierra Alhamilla, Graena, Jabalcuz y Lanjarón. ${ }^{43}$

Entre 1892 y 1897 se publicó la monumental obra de Leopoldo Martínez Reguera, médico con un marcado carácter humanista. ${ }^{44} \mathrm{Su}$ Bibliografía Hidrológico-Médica Española sigue siendo hoy un importante trabajo de referencia. ${ }^{45}$ La primera parte del segundo volumen (1896), dedicada a manuscritos y biografías, refleja bien las vicisitudes que sufrieron las memorias manuscritas hasta que llegaron a la Facultad de Medicina de la Universidad Complutense. ${ }^{46}$

Recuerda Martínez Reguera que las memorias anuales desde 1816 y las extraordinarias desde 1868 suponían millares de ejemplares que debían estar archivados en el Centro Superior de Sanidad y se queja de que son escasas las que se conservan por "haberse remesado en su mayor parte, bajo el erróneo concepto de documentos y como papel sobrante, al Archivo de Alcalá". ${ }^{47}$ El 1893 se requirió a dicho archivo para enviarlas a la Facultad de Medicina, pero sólo se recibieron 154 memorias manuscritas y 5 impresas. Una nota interna de este archivo indicaba que las memorias de los años 1844 a 1846 debían entregarse a la Comisión encargada de publicar el Manual de Baños, cosa que debió ocurrir, no existiendo constancia de su devolución.

\footnotetext{
Rubio 1853, XII-XIV.

Rubio 1853, 570-571.

4 Además de ser director de diferentes balnearios (Jabalcuz, Puertollano, Fuencaliente, Trillo, Alange, Arenosillo, Caldas de Malavella o La Salvadora entre otros) se licenció y más tarde doctoró en Derecho, realizó estudios de ciencias y pintura, fundó diferentes sociedades - como la de Bibliófilos Españoles, el Liceo Científico-Literario Español o el Instituto Médico de Barcelona- y perteneció entre otras instituciones a la Real Academia de la Historia, siendo desde 1874 su correspondiente en Córdoba: http:/dbe.rah.es/biografias/49295/leopoldomartinez-reguera [consultada el 23 de mayo de 2019].

45 Maraver 1997, 42.

46 Martínez Reguera 1896, XXXVII-XL.

47 Martínez Reguera 1896, XXXVII.
} 
Duda el autor de que el Archivo de Alcalá hubiera entregado todo el material que tenía, no por mala fe sino por desidia, y hace notar también las malas condiciones de la custodia en el Ministerio de Gobernación, donde los legajos se vendían al peso en las tiendas.

El problema se veía venir ya que recuerda que en la búsqueda realizada por el Dr. González Crespo de los manuscritos elaborados entre 1817 y 1823 (no aclara cuándo) "sólo encontró, de todo ese período, una (memoria) relativa al Molar, de D. Celestino Pérez, del año $1817^{\prime \prime 48}$ y lo achaca a la asunción de las funciones que tenía la Junta Superior Gubernativa de Medicina por el Protomedicato en 1821.

Por otra parte, esa falta de cuidado en la custodia de manuscritos provocó que algunos de estos acabasen en manos privadas, algunos de las cuales se pudieron recuperar. Concluye diciendo que:

Esparcidas andaban las Memorias entre el Archivo de Alcalá, el del Ministerio de la Gobernación y el de la Dirección general, hasta que, al constituirse, por el reglamento de 1874, la Comisión del Anuario oficial de las aguas minerales de España se empezaron á coleccionar bajo el cuidado de la misma, que tuvo que suspender su tarea al ser disuelta en 1889; y Dios sabe la suerte que las estaría reservada si el señor Alarcón, con plausible persistencia y apoyado por el Sr. Vincenti, no hubiera logrado una Real orden de traslación de todos esos folletos á la Biblioteca de la Facultad de Medicina, en donde se han de custodiar con mayor espacio y orden, para que así, ya que lamentamos la pérdida de los primitivos, puedan reservarse los contemporáneos como eslabones constitutivos de la cadena histórica de cada establecimiento, en cuyo contexto se nota la lucha incesante entre el Director, que pide reformas beneficiosas para los enfermos, y por ende para los intereses del dueño, y éste, que entendiendo, en la mayoría de casos, la cuestión al revés, se resiste á las mejoras, en su deseo de que del manantial brote el oro acuñado sin esfuerzo ninguno, y mira, por tanto, como enemigo al representante del Gobierno y de la humanidad. ${ }^{49}$

En los volúmenes dedicados a Manuscritos y Biografías, 2.1 (1896) y 2.2 (1897), Martínez Reguera recoge los manuscritos existentes en la biblioteca de la Facultad de Medicina y en la biblioteca de la Sociedad Española de Hidrología Médica. La mayoría son memorias médicas, pero también hay disertaciones acerca de aguas minero-medicinales y memorias de oposición. En el volumen 2.1 recoge desde 1752 $\left(n^{\circ} 26\right)$ hasta $1861\left(n^{\circ} 709\right) 170$ documentos pertenecientes a la Sociedad Española de Hidrología Médica y desde 1777 ( $\left.\mathrm{n}^{\circ} 34\right)$ hasta 1880 ( $\left.\mathrm{n}^{\circ} 1912\right) 1416$ manuscritos de la Facultad de Medicina. En el volumen 2.2 hay 2 trabajos de la Sociedad Española de Hidrología Médica, ambos sin año (nº 3119 y 3128$)$ y 706 de la biblioteca de la Facultad de Medicina desde $1881\left(\mathrm{n}^{\circ} 1913\right)$ hasta una memoria consignada en el grupo de las que carecen de fecha $\left(n^{\circ} 3136\right)$.

En total reúne 2483 manuscritos conservados hasta $1888^{50}$ en la Universidad Complutense, además de 172 de la Sociedad Española de Hidrología Médica y 1106

\footnotetext{
Martínez Reguera 1896, XXXVIII.

Martínez Reguera 1896, XXXVIII

50 Otra noticia informa que en 1894 ingresaron en la biblioteca 2145 memorias procedentes del Archivo General Central de Alcalá de Henares (Méndez 2007, 331-332). Aunque Martínez Reguera concluyó su obra con las
} 
de diversas procedencias, entre los que hay 25 que van desde el siglo X hasta el segundo tercio del siglo XIX.

Entre los años 1991-2004 fue director de la biblioteca de la facultad de Medicina de la Universidad Complutense D. Juan Antonio Méndez Aparicio. Uno de sus empeños fue catalogar los fondos manuscritos relacionados con los balnearios que, a su vez contienen en su interior, o añadidos como apéndices, documentos muy variados, como cuadros estadísticos, planos, fotografías, láminas o impresos.

El catálogo, heredero directo del de Martínez Reguera, recoge 3829 obras, casi mil más de las ofrecidas en la Bibliografía Hidrológico-Médica Española ya que, además de alguna memoria antigua adquirida, ${ }^{51}$ hay que sumar las producidas entre los años 1889 y 1928.

A la muerte de D. José Antonio Méndez la obra estaba prácticamente terminada y pocos años después, en 2008, fue publicada como número extraordinario de Anales de Hidrología Médica en su serie de monografías Balnea. Al contrario que Martínez Reguera, que utilizó un criterio estrictamente cronológico, Méndez organiza su catálogo con criterios geográficos y dentro de estos con un orden alfabético de comunidades autónomas, provincias y balnearios, siendo la cronología la que ordena los documentos de cada uno de los balnearios.

Por otra parte, en la actualidad 1479 manuscritos de los que componen esta colección de la Facultad de Medicina están digitalizados ${ }^{52}$ y son asequibles en la web. ${ }^{53}$

\section{Los manuscritos y la Historia Antigua: de la Arqueología a la Epigrafía}

Rubio ya estableció en función de los manuscritos conservados hasta 1850 y de la encuesta que realizó entre los médicos-directores de baños que había una serie de establecimientos con uso durante las épocas romana e islámica; aunque es una información que da a título de inventario, quedaba instituida la relación del termalismo decimonónico con el termalismo antiguo. Así, cuando en 1991 y 1996 se celebran respectivamente una mesa redonda y un congreso dedicados al termalismo antiguo, ${ }^{54}$ el profesor Maraver, director de la Cátedra de Hidrología Médica y la Escuela Profesional de Hidrología Médica e Hidroterapia de la Facultad de Medicina de la Universidad Complutense, retoma el tema y desde el ámbito de la medicina se centra en las aportaciones de los médicos-directores a la historia y la arqueología en función de los datos recogidos en sus memorias tanto impresas como manuscritas, ${ }^{55}$ además de indicar la topografía de estas últimas conservadas en la biblioteca de la Facultad de Medicina:

memorias de 1890, la publicación del primer tomo dedicado a los manuscritos no se produjo hasta dos años después de esta donación, por lo que estas memorias ya aparecen consignadas como pertenecientes a la Facultad de Medicina.

51 Por ejemplo la n 1499, correspondiente a Gómez Gabaldon 1822.

52 Corresponden a Obras Generales (61), Andalucía (278), Aragón (110), Baleares (22), Canarias (1), Cantabria (18), Castilla-León (33), Castilla-La Mancha (66), Cataluña (60), Madrid (27), Navarra (67), Valencia (84), Extremadura (38), Galicia (375), La Rioja (21), Vascongadas (135), Principado de Asturias (17) y Región de Murcia (66).

53 http://webs.ucm.es/BUCM/med/24632.php [consultada el 20 de mayo de 2019].

54 Peréx - Bazzana 1992; Peréx 1997.

55 Maraver 1992, 195-210; 1997, 41-48. 
(...) pudimos estudiar las tres mil trescientas setenta y una ${ }^{56}$ Memorias manuscritas que se custodian en la actualidad en la actualidad en ciento treinta nueve carpetas de los fondos.

Como resultado de su estudio podemos afirmar que el número de autores de tales memorias se eleva a seiscientos sesenta y cinco, ocupándose de un total de doscientos manantiales diferentes...Por último decidimos ocuparnos del número de Memorias manuscritas que correspondían a establecimientos balnearios documentados por la Arqueología, concretamente las de treinta y siete centros termales $(\ldots)^{57}$

\subsection{La veracidad de la información de los manuscritos}

Desde el siglo XIX ha existido una preocupación por poder relacionar el uso de las aguas minero-medicinales con un periodo histórico anterior, aunque es el romano el que ha despertado más interés. Como afirma Juan Antonio Rodríguez hay una verdadera tendencia a legitimar tanto las propiedades de las aguas como sus efectos terapéuticos haciendo uso de la antigüedad de los balnearios..$^{58}$

Son abundantes los ejemplos a este respecto y basta con citar un caso. En Lérida, en el valle de Les, hay un balneario en el que supuestamente apareció la siguiente inscripción: Lexi / deo / C(aius) Sabi(nus?) / Hort(i) f(ilius) ${ }^{59}$ y, aunque sabemos que es falsa, ${ }^{60}$ la información que da el propio establecimiento de sus orígenes es la siguiente:

El balneario "Baronía de Les" tiene el origen de su nombre en la época del dominio romano (ninfas y diosa Lex). Los baños termales cercanos a Les eran ya conocidos desde la antigüedad clásica. Se han encontrado altares votivos y otros objetos que atestiguan que en tiempos de la Antigua Roma ya servían como termas, habiendo sido visitadas por Pompeyo, encontrándose en la población inscripciones donde se da gracias a las ninfas y a la diosa Lex por la curación obtenida. ${ }^{61}$

Hay que considerar que en algunos casos los médicos-directores no reflejaban los datos objetivos de hallazgos ni ofrecían las descripciones de las infraestructuras en las que desarrollaban su función, sino que hacían interpretaciones que exageraban o adornaban la antigüedad del lugar en el que estaban destinados. Sin embargo, otras veces hablaban de hallazgos concretos o describían las instalaciones hidráulicas y hosteleras que consideraban obsoletas y con necesidad de modernización. En este

En el catálogo actual hay 3829 memorias.

Maraver 1997, 46.

58 Rodríguez 1997, 52-53. A este respecto el uso de la Antigüedad como argumento ha sido tratado en Gascó et alii 1993 y Gascó - Beltrán 1995. En el caso de los balnearios la competencia que hay entre ellos hace que se busquen todos los elementos diferenciadores para atraer a los bañistas. ¿Qué mejor argumento que afirmar que las aguas llevan dos mil años testadas? Hay que tener en cuenta que además del interés económico de los establecimientos, los médicos cobraban en función de las consultas realizadas. De todas maneras hay pocos casos en los que se inventara una antigüedad romana, pero en casi todos, cuando el uso de las aguas existió realmente, se enfatiza la romanidad de los baños.

59 Lara $1973,173, \mathrm{n}^{\circ} 70$.

60 Cf. Fabre et alii 1985, esto es IRC II 19; Díez de Velasco 1992, 388; 1998, 42.

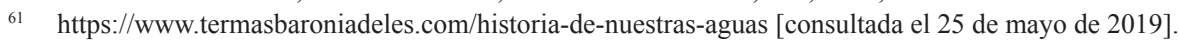


último caso nos acercan a un momento anterior al siglo XIX que, dada la falta de inversiones en los baños medicinales que se produce desde la época medieval, bien pudieran pertenecer a ésta o a la romana.

\subsection{El contenido de los manuscritos}

El objeto principal de las memorias que debían presentar cada año los médicos era llevar un registro de enfermedades, tratamientos y resultados de los mismos. Pero también se les pedía una historia general del lugar, incluida la natural, e incluso que dieran cuenta de las mejoras realizadas en los establecimientos.

Hasta los años 80 del siglo XIX en mayor o menor medida los informes respetan estos contenidos, mientras que entre finales de siglo y principios del siglo XX el material enviado por los médicos está compuesto fundamentalmente por cuadros resumen de enfermos, procedencias, enfermedades y tratamientos, lo que de entrada no parece utilizable para la Historia Antigua.

Desde luego la información "histórica", con todas las prevenciones que podamos tener, es especialmente útil. Cualquier referencia a hallazgos antiguos se suele encontrar allí. Muy relevante puede ser también la descripción de la realización de obras de mejora, ya que en esta se encuentra tanto la información acerca de lo que se quiere reformar como la posibilidad de hallazgos nuevos a causa de las remociones de tierras necesarias en algunos casos para hacer los cambios.

Hay ocasiones en que los manuscritos van acompañados de croquis, planos y alzados, lo que también puede aportar datos interesantes.

\subsection{La información arqueológica}

Son muchas las memorias de las que se puede extraer información acerca de la fase romana; a veces de forma directa, ya que mencionan hallazgos explícitos asociados a estructuras, y a veces de manera indirecta, puesto que la propia naturaleza de la descripción o información obtenida por otras fuentes hacen seguro o bastante posible que se trate de restos romanos. Veamos dos ejemplos.

\section{Baños de Ledesma}

Situados a $27 \mathrm{~km}$ al noroeste de Salamanca, junto al cauce del Tormes. Conocemos breves descripciones aparecidas en libros impresos a partir del siglo XVII. Así tenemos la de González Dávila, ${ }^{62}$ la de Colmenero ${ }^{63}$ o la de Dorado. ${ }^{64}$ Sin embargo, la más completa de todas se encuentra en el manuscrito del coronel de infantería D. Ramón Moya fechado en 1915 que, aunque no sea memoria de médico-director, está incluido en la colección de manuscritos de médicos de balnearios de la Universidad Complutense.

Además del baño principal, cuyo edificio y piscina describe con todo lujo de detalles y con medidas precisas, ${ }^{65}$ muestra la existencia de diferentes restos que

\footnotetext{
Dávila 1606, 259.

Colmenero 1697, 57.

Dorado $1776,44$.

Moya 1815, 14-31.
} 
identifica con otros baños ${ }^{66}$ y con una hospedería, además de recoger el hallazgo de "urnas sepulcrales". ${ }^{67}$

No hay la más mínima duda acerca de que el edificio cubierto por bóveda en que estaba la piscina es romano de lo que queda constancia, por ejemplo, en la bibliografía de principios del siglo $\mathrm{XX}^{68}$ y por mi propia visita al balneario donde pude ver los ladrillos bidepales procedentes del desmonte parcial del frente del edificio.

\section{Baños de Zújar}

Desaparecidos bajo las aguas del pantano de Negratín, se encontraban $20 \mathrm{~km}$ al norte de la ciudad de Baza (Granada). De su origen romano no hay dudas ${ }^{69}$ y hasta poco antes de su colapso todavía se podían apreciar restos de esta época.

Los datos más antiguos son del siglo XVII, fecha en que se presume ya la construcción romana. ${ }^{70}$ De finales del XVIII es una descripción algo más completa en la que se informa de que parte de la edificación que hoy aceptamos como romana se ha derrumbado. ${ }^{71}$ Sin embargo, las noticias que ofrecen los distintos autores son caóticas y en ellas no aparece una sola medida. Habrá que esperar a 1877 para tener la primera descripción pormenorizada del balneario recogida en la memoria de la temporada de 1877 del entonces director-médico D. Eduardo Palomares:

El balneario lo constituyen dos galerías unidas en ángulo recto, una más alta en donde están las puertas de las estufas, y otra más baja que sirve de repartidor a los baños particulares o cuartos de las pilas. El seno de dicho ángulo mira al norte y en el está comprendido el baño general para la clase acomodada y el baño de pobres. (...) a la derecha hay 6 puertas en muy mal estado que dan entrada a otras tantas estufas; siendo estas habitaciones embobedadas, de 4 metros de longitud por 3 de anchura, embaldosadas con piedra de sillería y con una escalera de piedra cada una para bajar al baño general; (...) El baño general es una gran alberca descubierta rodeada de un poyo; tiene la figura de un cuadrilátero irregular cuyos lados tienen las siguientes dimensiones 8,20 metros, 4,60 m., 6,5 m., $6.30 \mathrm{~m}$. y se llena hasta 1,40 m., teniendo una profundidad de 3,15 m.; esta alberca, por los lados de menor longitud y por el de la mayor está rodeada en su fondo por una galería que tiene tres arcos en este y dos en aquellos; dicha galería tiene un metro de anchura y su cubierta forma el pavimento que hay alrededor del poyo de la alberca. En el lado de los tres arcos hay cinco comunicaciones con otras tantas alberquitas cubiertas, de 9 metros cuadrados aproximadamente a las que se baja por las escaleras que hay en las estufas, el techo de estas albercas está formado por el suelo de la primera galería descrita y están rodeadas de tres gradas a distintas alturas $(\ldots)^{72}$

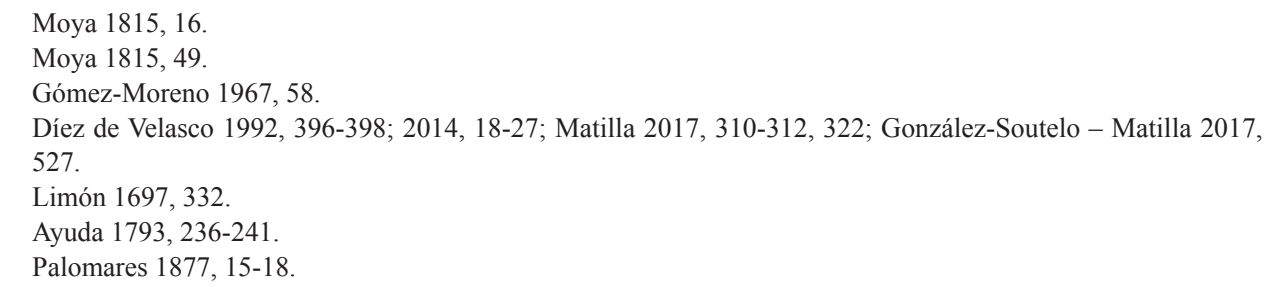


Las diferentes descripciones y en especial la del médico-director permiten que este baño se pueda comparar, entre otros, con los balnearios romanos de Fortuna, São Pedro do Sul, Caldas de Montbui y Caldas de Malavella. ${ }^{73}$

\subsection{La información numismática}

La numismática suele aparecer en las memorias de forma imprecisa: “(...) en las últimas modificaciones hechas en sus balsas para profundizarlas, se han hallado varias monedas que pertenecieron a los romanos, pues en ellas se ven grabados los nombres y bustos de los Césares (...)", ${ }^{74}$ siendo bastante habitual presentarlas en un contexto todavía más general, como se puede ver en las memorias de Baños de Molgas $^{75}$ o en las de Tiermas:

Entre las ruinas he encontrado algunas monedas y medallas de plata romanas, bastante desgastadas en su mayor parte, que he entregado al Excmo. Sr. D. Alejandro Olivan, propietario del establecimiento. En las inmediaciones del pueblo y en los campos próximos á los baños se han encontrado algunas losas sepulcrales, sin inscripciones algunas de ellas, y las demás las tenían tan estropeadas que no nos han permitido descifrar á quiénes pertenecían ni su antigüedad. ${ }^{76}$

Entre los ejemplos más llamativos respecto a la aparición de monedas en los balnearios o en su contexto tenemos el de Aguas de Busot. En la memoria del año 1844 leemos lo siguiente:

Las excavaciones practicadas en el baño Romano donde se encontraron monedas con el nombre de Julio Cesar, anillos ecuestres, vasos de barro Saguntino (...) Conservo algunas monedas de las dichas, y de Tiberio encontradas en la citada excavación. ${ }^{77}$

En 1849 describe Joaquín Fernández López las monedas que mencionaba en 1844. Se trata de 18 piezas a las que añade la referencia de otras 10 de Augusto, Julio César, Claudio, Nerón y Tiberio.

Las descripciones son peculiares, evidentemente realizadas por un profano, aunque la mayoría se pueden identificar, por lo que la información es de bastante utilidad y permite plantear un momento álgido del balneario entre los siglos I a.C.-I d.C. y otro de uso en el siglo IV d.C. Basten dos ejemplos:

73 Matilla - Egea 2015, 885 .

74 Castillo 1845, 15. Se trata de una memoria impresa sobre los baños de Alhama de Murcia que se corresponde con la memoria manuscrita del año 1845, que en la actualidad está perdida.

75 Caña 1880; Pita 1885.

76 Lletget 1857, 12. Tomás Lletget estuvo en 1856 de director de los Baños de Tiermas (Gaceta de Madrid 1194, de 11 de abril de 1856, 2), ganando la plaza de Fitero viejo en 1857 (Gaceta de Madrid 1543, de 27 de marzo de 1857, 2). La memoria manuscrita del año 1856 se ha perdido, pero se publicó por partes en diferentes números de la Gaceta de Madrid (1534, 1537, 1541 y 1543, de marzo de 1857), siendo después editada como monografía por la Imprenta Nacional. Lletget responde al tipo de médico culto e interesado por la historia que siempre se informa de los restos aparecidos en los establecimientos que dirige (tanto en el pasado como cuando llega a estos). Otro ejemplo de su interés lo encontramos en las memorias de Fitero (Lletget 1870, 226-240), donde entre otras cosas especifica el hallazgo de monedas de Augusto y Tiberio, algunas de los municipios de Celsa, Turiasu y Cascantum (Lletget 1870, 228-229).

77 Fernández López 1844, 28. 
4. ${ }^{\mathrm{a}}$ Moneda mayor del tamaño de una pieza de dos cuartos de mas borde y peso, y de bronce; presenta por un lado un busto, en mi concepto, de Mercurio, porque representa esculpida una fisonomía de un joven imberbe con casco alado. El lema que lo circunda no he podido leerlo, ni tampoco el del dorso donde se ve como un dragón que cruza de una á otra parte, y por medio de él cinco saetas ó rayos, cuyas puntas miran si se pone de canto la moneda, al lado derecho como la cara del Dios $(\ldots)$

(...)

7. ${ }^{\mathrm{a}}$ Moneda de plata bien conservada en figura de óvalo del diámetro de un real de plata en que se ven distintamente por un lado un busto de un anciano con casco orlado de arrayán, sin ningún lema, y en el otro una ninfa en traje talar (la Victoria) con alas. Tiene una corona en la mano derecha que cubre unos trofeos. En el pedestal de estos se lee Roma. Me parece recuerdo de algún triunfo. ${ }^{78}$

En estos dos casos se trata de un as de Valentia de época de Augusto y de un victoriato de la primera mitad del siglo II a.C. ${ }^{79}$ El médico confundió en la moneda de Valentia la cabeza galeada de Roma con la de Mercurio y la cornucopia sobre el haz de rayos de Júpiter con el dragón y las saetas; del mismo modo, en el victoriato el anciano con "casco orlado de arrayán" es Júpiter laureado, si bien la descripción del reverso se acerca bastante a lo que es: una victoria ante un trofeo militar con ROMA bajo la línea de exergo.

\subsection{La información epigráfica}

Hay suficientes ejemplos de la misma para que merezca la pena realizar una revisión de las memorias. Desgraciadamente la mayoría de las que se conservan (último tercio del XIX) son de una época en la que los cuadros estadísticos priman sobre las consideraciones históricas.

A veces las noticias que se dan son imprecisas (como las referentes a las monedas) y además contradictorias. Así en la memoria manuscrita que Anastasio Chinchilla, director-médico de los Baños de Villatoya (Albacete), hace en 1858 dice lo siguiente sobre la antigüedad del uso de las aguas:

Las aguas minerales de Villa-toya han yacido en el olvido de los médicos y escritores por espacio de muchos siglos. Ni Lucio Marineo Siculo, que detenidamente habla de algunas fuentes de España, ni Antunez en sus memorias historicas de España, ni medico alguno han mencionado estas fuentes. D. Jose Genovés y Tamarit, Director interino de estas aguas fue el primero que publicó una Memoria sobre sus virtudes. despues de éste, no conozco á ningún otro autor que haya publicado sus observaciones.

No ha sucedido lo mismo respeto de los pueblos de las poblaciones contiguas; quienes conservando tradicionalmente de generacion en generacion los beneficios que de su uso recibian sus familias, han contribuido á la justa reputacion que entre ellos tienen esas aguas. ${ }^{80}$

Fernández López 1849, 39.

Arias - Matilla 2011, 727.

Chinchilla 1858, 71. 
Este documento, donde los rasgos de antigüedad del balneario son más que genéricos, no menciona en ninguna de sus hojas la epigrafía ni dato alguno que tenga que ver con el mundo romano. Un año después, en 1859, Chinchilla imprime esta obra con algunos cambios que estriban básicamente en una diferente ordenación de las materias tratadas y, sin embargo, la edición impresa unos meses después de finalizar la manuscrita ${ }^{81}$ sí que parece mencionar, aunque de forma genérica, la aparición de epígrafes, como se puede constatar en los párrafos que se corresponden con los anteriores:

Las aguas minerales de Villatoya han permanecido por espacio de muchos siglos en el olvido de los médicos. Vestigios que se han descubierto en varias escavaciones, demuestran que estos baños fueron muy frecuentados y conocidos desde el Imperio romano. Así lo demuestran las lápidas y fragmentos de sepulcros que se han encontrado.

Pero si las virtudes de estas aguas yacieron sepultadas para la ciencia de curar, no sucedió lo mismo respecto de los pueblos comarcanos, cuyas gentes, conservando tradicionalmente, y pasando de generacion en generacion los beneficios que sus familias obtuvieron del uso de sus aguas, han contribuido á su justa celebridad. ${ }^{82}$

En un caso como éste queda la duda de si la información ofrecida es pura retórica o por el contrario se ajusta a la realidad, ya que de Villatoya/Fuente Podrida ${ }^{83}$ conocemos el epitafio de Lucana, ${ }^{84}$ que según Hübner apareció en la aldea de Cilanco, a $3 \mathrm{~km}$ de Villatoya y de Fuente Podrida, ${ }^{85}$ pero que también pudo encontrarse en el término de Requena. ${ }^{86}$ En ambos supuestos podría encajar con lo que decía el médico en la edición impresa.

Tres ejercicios de oposición de 1829 referentes a los baños de Alange dan información histórica o epigráfica de muy diferente manera. En uno prima la imprecisión, en otro el texto de la inscripción dedicada a Juno Regina ${ }^{87}$ se parafrasea, mientras que en el tercero se recoge con cierta fidelidad un epígrafe problemático: ${ }^{88}$

En sus inmediaciones se encuentran varios vestigios del buen aprecio que hicieron los antiguos de estos baños. ${ }^{89}$

Diferentes monumentos prueban la antigüedad de estos baños, entre ellos el voto que hicieron los padres de Varina Serena a la Diosa Juno por haberse restablecido su hija por el uso de dichas aguas..$^{90}$

En sus alrededores y contiguos al edificio, se notan anchos cimientos de otras piezas muy espaciosas con separaciones para muchos enfermos, y por un cañon

\footnotetext{
Está fechada en Sevilla el 12 de diciembre de 1858.

Chinchilla 1859, 38-39.

3 El balneario de Villatoya está en la margen derecha del río Cabriel, en Albacete, mientras que Fuente Podrida se encuentra en la margen izquierda, a 1,5 km del anterior, en el término de Requena, Valencia. Ni siquiera en la actualidad es fácil determinar si los restos aparecidos en la zona son de uno u otro lugar (González-Soutelo Matilla 2017, 565).

${ }^{84}$ CIL II 3551 (=ILER 2885).

85 Abascal 1990, 13.

86 Corell 2008, 255-256, XVII.

87 CIL II 1024 (=ILER 361 = AE 1972, $245=A E$ 1997, 805).

88 CIL II 466 (=ERAE 5).

89 Mendoza $1829,13 \mathrm{v}$.

90 Cisternes 1929, 20-21.
} 
de bobeda en otra direccion se marchaba a otras piezas separadas de los baños que en el día cuasi son subterraneas y en que apenas se puede entrar sin la linterna de Davi, y apesar de estar terraplenadas, se notan claramente dos ordenes de alcobas arqueadas, emulando un claustro de romanos conventos, todo de bobedas, y en una piedra medio soportada con mucha dificultad se léé la siguiente inscripción: : Fontibus / Sacrum /Julia Lupa /V.S.L.M..$^{91}$

Este último aspirante también describe el altar de Varinia Serena ${ }^{92}$ pero, como en la inscripción de Julia Lupa, lo hace en cursiva ordinaria, eso sí, respetando las diferentes líneas del texto y marcando alguno de los signos de interpunción. Aparentemente la copia que nos ofrece la hizo de la observación directa del ara ya que en la cuarta línea no consigue leer Flaccina ni C.F. y lo resuelve así: “...Accina. ${ }^{93}$ C.I.". Además anota que el V.C. de la tercera línea significa Vir Consularis y lo que lee como C.I. en la línea siguiente lo interpreta como Corpux Incomposobilis. Aun así, si vio esta inscripción habría que suponer que también tuvo que leer la otra, que en la actualidad se conserva en el Museo Arqueológico Nacional.

Efectivamente, diferentes sensibilidades respecto a la historia hacen que los restos romanos se mencionen de maneras muy diversas y en cualquiera de los casos todos esos datos podrían servir. El problema lo tenemos cuando constatamos que alguna de las informaciones es falsa, como ocurre con el ejercicio de Rafael de Cáceres, que de ninguna manera pudo ver la inscripción de Julia Lupa en Alange durante 1829 ya que por Antonio Ponz sabemos que ésta se encontró en Mérida y la descripción del lugar en que se hallaba no deja ninguna duda:

En casa de D. Vicente García de la Rocha, enfrente de la puerta de Santa María, llamada de los perdones, hay estas dos:

FONTIBVS

SACRVM

IVLIA LVPA

M.L.V S (137)

Cuyas últimas letras de la segunda parte parece están trocadas, y que habían de leerse así: V.S.L.M. esto es, Votum solvit libens merito. Debaxo de esta inscripción hay un bellísimo capitel corintio, y una célebre estatua consular, á la qual faltan los pies, y la cabeza, y es de lo mejor que se encuentra en Mérida de escultura. ${ }^{94}$

Ya se ha comentado a propósito de los epígrafes de Les (Lérida) que a veces, por motivos de publicidad y prestigio, los dueños o directores de los balnearios se inventaban hallazgos. No es el caso, ya que estamos ante un ejercicio de oposición sin posibilidades de difusión más allá del tribunal que lo juzgaba y no se puede explicar sino en un intento de impresionar a dicho tribunal con un conocimiento mayor de estos baños que el de todos sus contrincantes. En todo caso ¿qué médico iba a dudar de que en Alange pudiera haber una inscripción romana dedicada a las aguas minero-medicinales?

\footnotetext{
Cáceres 1829, 23-24. A propósito de este manuscrito se puede consultar Carmona 2008, 43-48.

Cáceres 1829, 24.

Exactamente igual que Ambrosio de Morales 1575, 97v.

Ponz 1778, 137-138; CIL II 466.
} 
Para terminar con los ejemplos de epigrafía quiero traer a colación la memoria de 1845 de Caldas de Montbui (en realidad es la más antigua de las conservadas de este balneario en la Facultad de Medicina) del director-médico Ignacio Graells. Se trata de un informe extraordinario elaborado a petición de la comisión nacional encargada de redactar el manual de aguas termales. De las 120 páginas de que consta, dedica 8 a la historia romana de la villa, ${ }^{95}$ ocupando la epigrafía la mayor parte de éstas, aunque describe los baños romanos y menciona algunas monedas (Augusto, Germánico y Antonino Pío).

Las inscripciones que cita y dibuja son, en este orden: CIL II 4488, CIL II 4493, CIL II 4489, CIL II 4487, CIL II 4492, CIL II 4490 y CIL II 4491 (Fig.1). Da información acerca del lugar y las circunstancias del hallazgo, así como del sitio donde se conservaban en 1845, a la vez que recoge la existencia de otros tres epígrafes que considera ilegibles. Fidel Fita en su trabajo "Lápidas romanas de Caldas de Mombuy. Datos inéditos", publicado en el Boletín de la Real Academia de la Historia 44 de 1904, comienza diciendo que va a utilizar el habla del manuscrito del Dr. Graells, que fecha en 1847 (puede que sea una copia posterior) y transcribe literalmente lo relacionado con la epigrafía, incluidos los dibujos de las lápidas. ${ }^{96}$ Creo que este dato es representativo de lo que estas memorias médicas pueden suponer para el estudio de la epigrafía y desde luego de la Antigüedad.
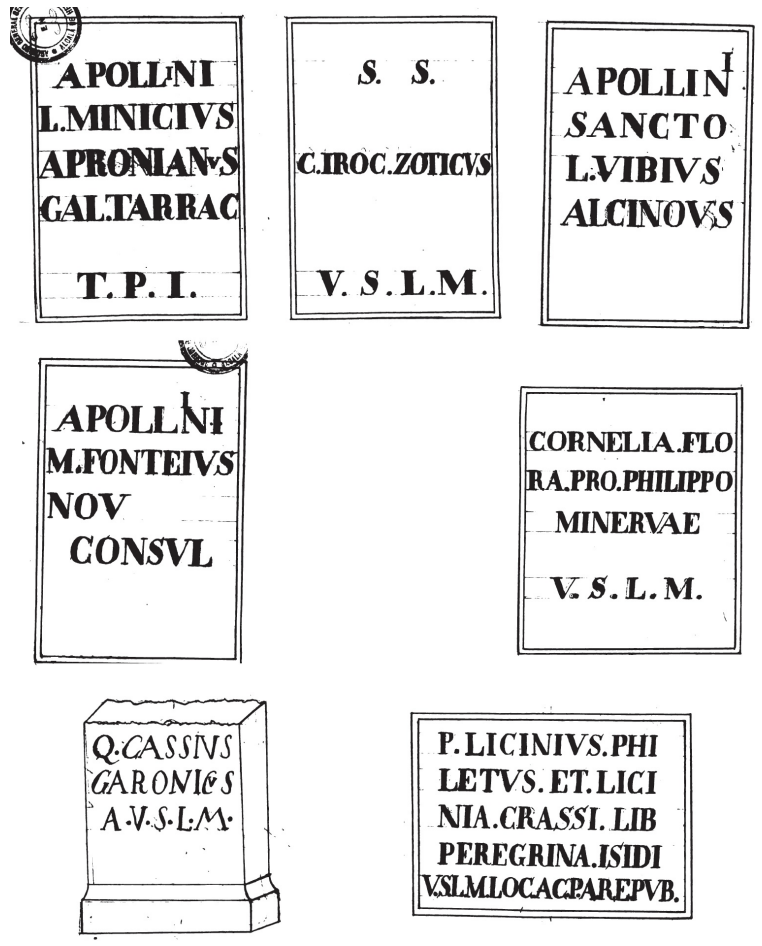

\section{P.LICINIVS.PHI \\ LETVS. ET.LICI \\ NIA.CRASSI. LIB \\ PEREGRINA.ISIDI \\ VMLLLOCACPAREPVB.}

Fig. 1. Inscripciones de Caldas de Montbui (Barcelona) recogidas en 1845 en el manuscrito de Ignacio Graells (Graells 1845, 6-8, 10).

\footnotetext{
Graells 1845, 2-9.
}

96 Fita 1904, 184-188. 


\subsection{La información gráfica}

A veces los manuscritos incluyen algún croquis o añaden planos exentos al texto de instalaciones existentes o de proyectos nuevos (además de, como se ha visto, dibujos de lápidas). Algunos de estos aportan datos de balnearios romanos o del estado de los baños de finales del siglo XVIII, lo que también ayuda a comprender estas instalaciones en el mundo antiguo.

\section{PLAN口 DEL, ESTAELECIMIENTI DE BAÑS}

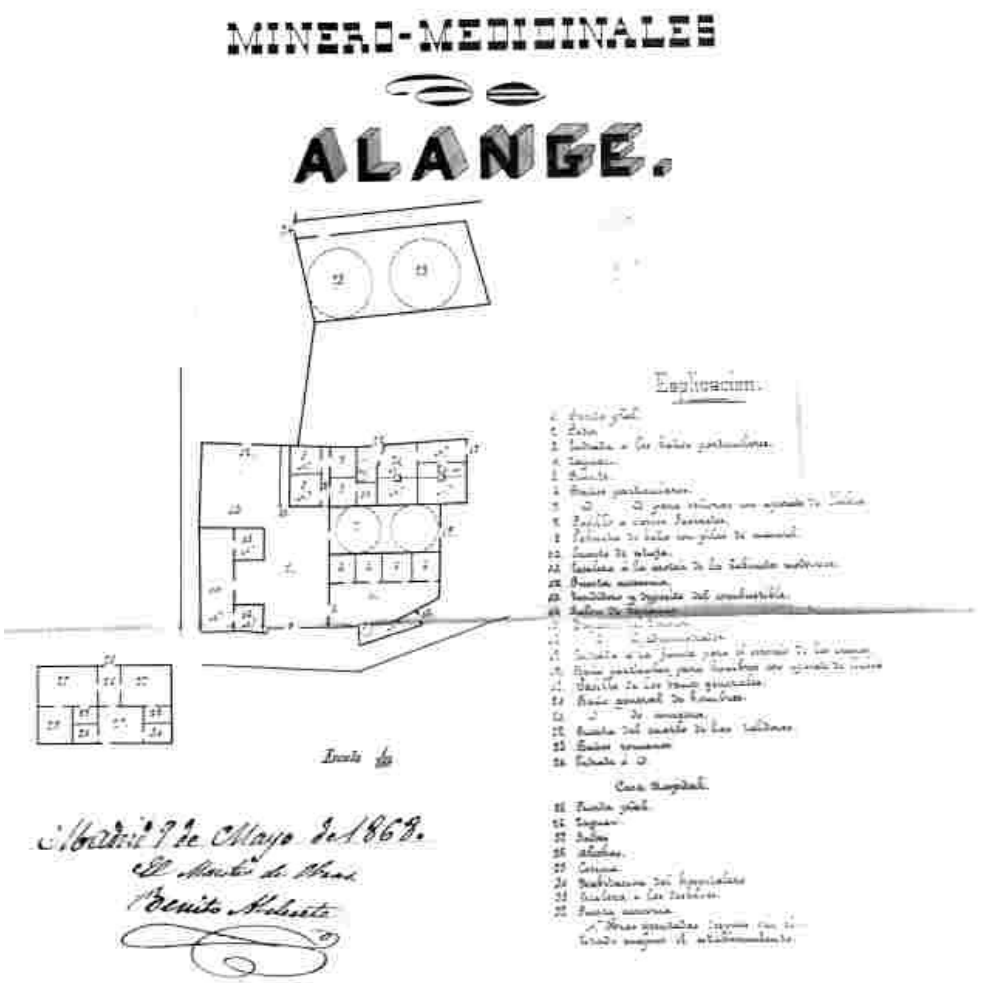

Fig. 2. Plano del balneario de Alange (Badajoz) realizado en 1868 por Abdón Berbén (Berbén 1868, 9).

En algunos casos resulta evidente la conexión entre el plano y la antigüedad, como ocurre con el de Alange recogido en la descripción que en 1868 realiza Abdón Berbén, dueño de los mismos ${ }^{97}$ (Fig. 2). En otros esa evidencia no es manifiesta, como en el plano de las nuevas instalaciones de Fortuna (Murcia) ${ }^{98}$ y en el proyecto de un nuevo balneario en Jamilena (Jaén); ${ }^{99}$ ambos, como el de Alange de 1868, son consecuencia del nuevo reglamento de baños que ese año entró en vigor. 
En Jamilena se hace un proyecto de nuevas instalaciones (Fig. 3) formado por el arquitecto Manuel Mostaza que se desarrolla a partir de la infraestructura existente, que consistía en dos pequeñas piscinas circulares. Ambas son romanas y responden al tipo de las que hay en los baños romanos de Fitero (Navarra). ${ }^{100}$ En la actualidad una está soterrada bajo el camino de entrada a un moderno chalet y la otra se conserva en un huerto, aunque enmascarada bajo una gruesa capa de pintura azul hidrófuga. ${ }^{101}$

En cuanto a Fortuna, el cambio en la ubicación de la surgencia provocó el abandono del balneario tradicional y la construcción de uno nuevo a $300 \mathrm{~m}$ del antiguo. El plano realizado para reflejar la situación del momento recoge una amplia porción de terreno (Fig. 4) en el que se encuentran los baños recién abandonados y los baños viejos, que vienen marcados en la leyenda (Fig. 5). También se aprecia la situación de una depresión casi circular junto a ellos. Las primeras campañas de excavaciones (1999-2003) se planificaron teniendo en cuenta esa información, pudiendo constatarse que esa depresión correspondía en parte al ninfeo donde estaba la surgencia romana y en parte a la piscina de la misma época y que lo marcado como Baños Viejos eran habitaciones de hospedaje de los siglos XVII y XVIII que reutilizaban el fonduq ${ }^{102}$ (fonda) del balneario islámico. ${ }^{103}$

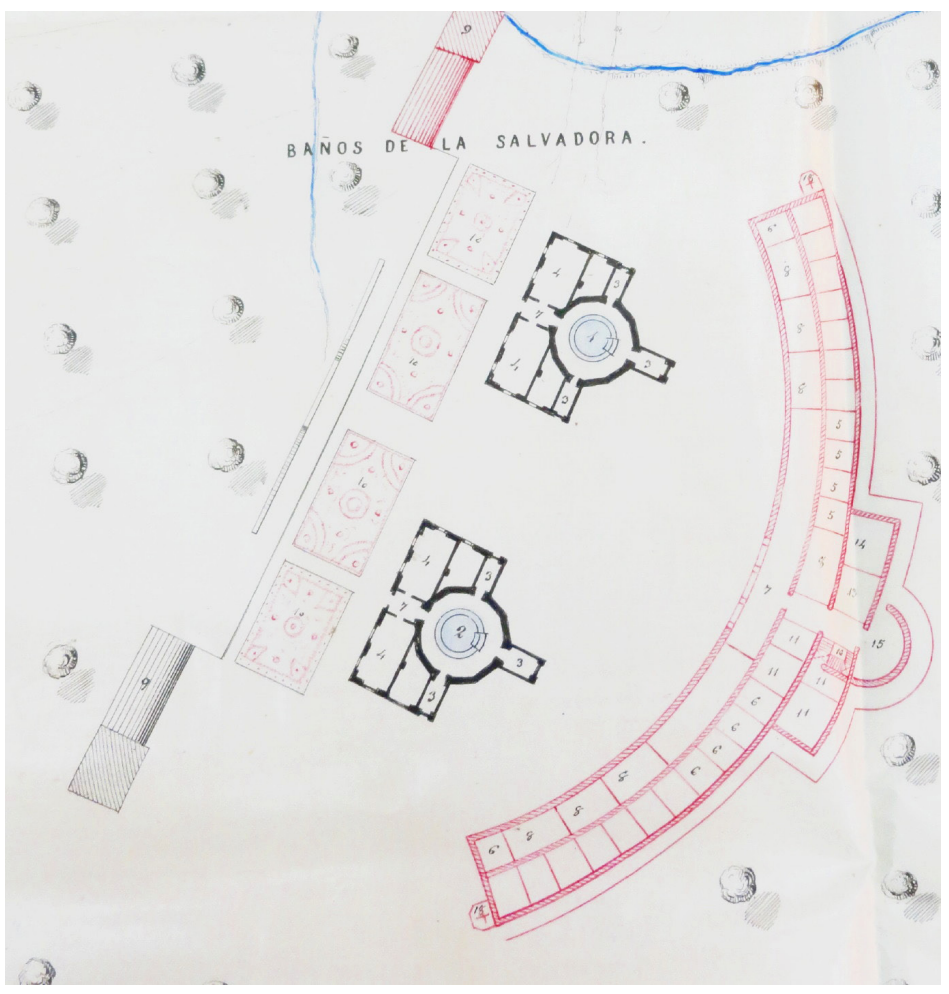

Fig. 3. Plano del arquitecto Manuel Mostaza proponiendo las nuevas instalaciones del balneario de Jamilena (Jaén) en torno a las dos piscinas circulares romanas (Mostaza 1868).

\footnotetext{
Medrano - Díaz 2005, 183-184; Mezquíriz 1986, 543-545.

101 González-Soutelo - Matilla 2017, 523.

102 Pérez-Asensio 2017, 434.

103 Matilla et alii 2003, 90-93.
} 


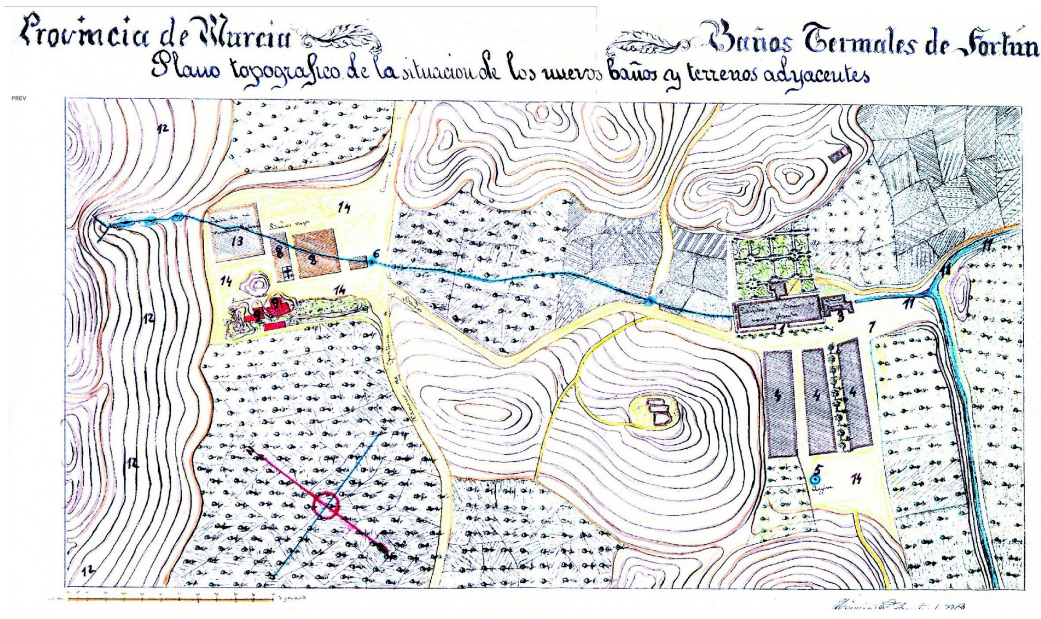

Fig. 4. Plano del Balneario de Fortuna en 1868 mostrando las nuevas instalaciones y la zona de restos romanos (Cascales 1868).

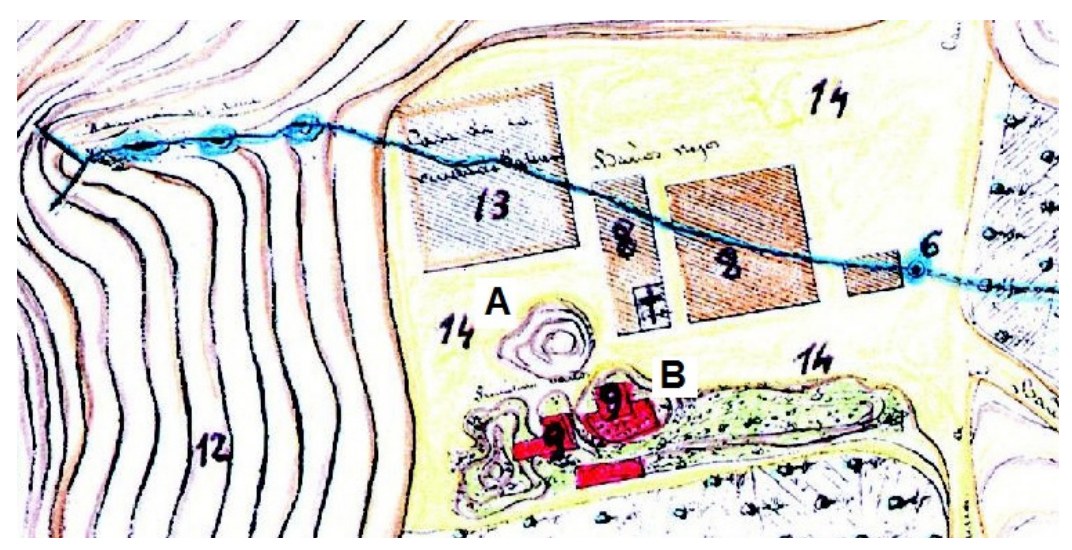

Fig. 5. Plano del Balneario de Fortuna en 1868. Detalle la zona con restos romanos. Señalización moderna: A. Ninfeo y piscina romanos: B. Habitaciones del siglo XVII aprovechando las estructuras anteriores islámicas y romanas. Numeración antigua: 6 .

Registro del manantial; 8. Baños del siglo XVII: Caballerizas, Capilla del Cristo de la Salud y alojamientos; 9. Según la leyenda del plano instalaciones de los Baños Viejos; 12. Canteras; 13. Baños del siglo XVII: Hospedería para familias. 14. Ejidos.

\subsection{Otras informaciones}

Aunque excede el ámbito y la intención de este trabajo, quiero dejar constancia de la rica información climatológica, botánica y zoológica que en muchas de estas memorias está contenida. El valor estriba en que se refleja de manera concreta el ambiente natural de un punto específico de la geografía durante el siglo XIX. Al margen del interés evidente que esto tiene para botánicos, ecólogos, zoólogos, etc., sirve de punto de contraste para los estudios específicos de flora y fauna que 
se pueden realizar con los datos de este tipo obtenidos en las excavaciones de los balnearios romanos.

Como ejemplo se puede citar la memoria escrita por el médico José Medel y Cano sobre Horcajo de Lucena en $1868 .{ }^{104}$

\section{Conclusión}

Por todo lo visto es indudable que los manuscritos sobre balnearios conservados en la Biblioteca de la Facultad de Medicina de la Universidad Complutense de Madrid aportan información importante, y muchas veces no conocida por otras fuentes, acerca de la arqueología, la numismática y la epigrafía romanas.

Los restos materiales de instalaciones romanas que han perdurado hasta la actualidad permiten conocer algunos lugares donde hubo uso de las aguas mineromedicinales entre los siglos I y IV d.C., pero para otros la única conexión entre surgencias curativas y Antigüedad son los datos contenidos en las memorias de los médicos directores, como se puede constatar en Horcajo de Lucena (Córdoba), Aguas de Busot (Alicante) o Alcantud (Cuenca). Por otra parte, la evidencia del origen romano de algunas instalaciones no permite saber cómo pudieron ser éstas en su origen o, en todo caso, en alguno de los momentos de su uso antiguo. En este asunto también los manuscritos ilustran nuestros conocimientos. Fitero (Navarra), Zújar (Granada) o Ledesma (Salamanca) son paradigmáticos a este respecto.

Además, como memorias médicas, reflejan tanto las infraestructuras hidráulicas como las enfermedades y las técnicas de aplicación de las aguas minero-medicinales, lo que hace que estemos ante los testimonios más antiguos de para qué y cómo se utilizaba cada uno de estos manantiales. El poco avance de la medicina hasta mediados del XIX y el reflejo que muchos de estos documentos hacen de los usos tradicionales del agua, permite hipotetizar si esa tradición en el uso podría entroncarse directamente con el mundo antiguo. En cualquier caso, los documentos más apropiados para empezar a estudiar esta cuestión son los más escasos, los que van desde la segunda hasta la tercera década del siglo XIX.

104 Medel 1868. Esta memoria de 57 páginas manuscritas se halla dividida en cuatro partes. La primera (1-15) es una descripción de las instalaciones hidráulicas ("nace el agua en el pavimento de una de las dos albercas (...) una para (...) hombres y la otra para las mugeres", hay "dos o tres pilones de barro para baños particulares") y de las hosteleras, donde describe tres hospederías con su capacidad y medidas, un "pequeño templo" dedicado a la Virgen de la Salud, además de hacer referencia al "refugio de pobres" (primitiva hospedería). No faltan las quejas del médico sobre el dueño de los baños que no ha invertido ni en comodidades ni en aparatología de hidroterapia. Habla asimismo de la topografía, con la situación en coordenadas geográficas y la descripción de la comarca con sus accidentes geográficos, vías de comunicación, producciones agrícolas, etc., además de reflejar cómo era la fuente; continúa con un capítulo que titula "Distracciones, alimentación, monumentos, curiosidades y paseos", que es un somero recorrido por la vida cotidiana del balneario, en la que destaca los pocos entretenimientos que hay, siendo uno de estos el paseo por las inmediaciones, donde los bañistas pueden ver "tegulas romanas, sepulcros, vasos lacrimatorios, ebillas y monedas (...) estatuas, fragmentos de columnas, tinajas, pedazos de utensilios de hierro derretidos (...) de alfareria"; la termina informando de las distancias a las principales poblaciones y medios de comunicación que se pueden usar para ir al balneario. La segunda (15-32) la dedica a las aguas minero-medicinales: su estudio, las propiedades físicas y químicas, los ensayos analíticos realizados y la acción fisiológica y terapéutica de las mismas, destinando un amplio capítulo a la geología de la zona. La tercera (33-43) en su conjunto recoge la historia médica de la comarca. La cuarta y última (44-57) se limita al estudio de 13 casos de bañistas que asistieron durante 1868 a Horcajo de Lucena. 


\section{Tabla 1}

\begin{tabular}{|c|c|c|c|c|}
\hline \multicolumn{2}{|l|}{$\begin{array}{l}\text { Balneario y número } \\
\text { total de manuscritos } \\
\text { conservados }\end{array}$} & $\begin{array}{c}\text { Otros } \\
\text { Manuscritos }\end{array}$ & \multirow{2}{*}{$\begin{array}{l}\text { Oposiciones } \\
1817(2), \\
1822, \\
1829(14)\end{array}$} & \multirow{2}{*}{ 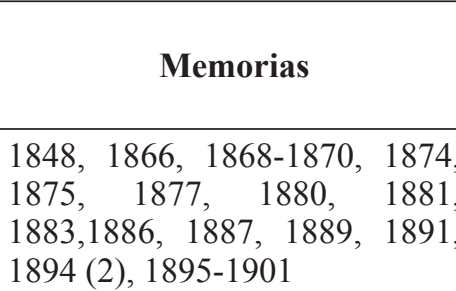 } \\
\hline Trillo & 47 & $\begin{array}{ll}1785, & 1788 \\
(2), & \\
1789, & 1819, \\
1845 & \end{array}$ & & \\
\hline Archena & 38 & 1841,1886 & $1829(7)$ & $\begin{array}{l}1845,1860-1866,1872,1877- \\
1879, \quad 1881-1888,1890-1892, \\
1894,1895,1897-1900\end{array}$ \\
\hline El Molar & 33 & & $\begin{array}{l}1826(6) \\
1838(8)\end{array}$ & $\begin{array}{l}\text { 1872, 1877-1884, 1891, 1892, } \\
\text { 1894- } 1901\end{array}$ \\
\hline Alcantud & 5 & & 1817 & $1863,1877,1878,1881$ \\
\hline Solán de Cabras & 18 & 1844 & $\begin{array}{l}1817(3) \\
1866\end{array}$ & $\begin{array}{l}1848,1857,1860,1861 \text { (2), } \\
1862,1863,1866,1868,1877, \\
1879,1882,1883\end{array}$ \\
\hline Puertollano & 32 & & 1817,1818 & $\begin{array}{lll}1860- & 1865,1868 & (2), 1870- \\
1875, & 1878-1888, & 1890-1893, \\
1896\end{array}$ \\
\hline Ledesma & 32 & $\begin{array}{l}1815(2) \\
1845\end{array}$ & & $\begin{array}{l}1821-1822,1871-1873, \quad 1876- \\
1879,1881-1901\end{array}$ \\
\hline Arnedillo & 50 & $\begin{array}{ll}18 ? ?, & 1817, \\
1844 & \end{array}$ & $1838(9)$ & $\begin{array}{l}1817,1848,1850,1860-1866, \\
1871-1873,1877 \quad(2), 1878- \\
1880,1882-1887,1889-1901, \\
1922 \text { (quinquenio) }\end{array}$ \\
\hline Quinto & 29 & 1844 & $1817(2)$ & $\begin{array}{l}1818,1848,1860,1862-1866, \\
1868,1870,1876,1877,1880, \\
1882,1885-1888,1891,1894, \\
1895,1897-1901\end{array}$ \\
\hline Alhama de Aragón 3 & 39 & 1879,1883 & 1817 & $\begin{array}{l}1849,1860-1866,1868,1871- \\
1873,1876,1879-1881,1883- \\
1901,1920 \text { (quinquenio) }\end{array}$ \\
\hline Tiermas & 50 & 1845 & $1833(12)$ & $\begin{array}{l}1844,1846,1848,1849,1856, \\
1860-1863,1865,1869-1873, \\
1877-1886,1888,1889,1891- \\
1901\end{array}$ \\
\hline Panticosa & 57 & & $1833(15)$ & $\begin{array}{l}1817,1842,1849,{ }^{105} 1861-1863, \\
1865,1866,1870-1875,1877- \\
1879,1880(3), 1881,1882, \\
1884-1888,1890-1901,1903\end{array}$ \\
\hline
\end{tabular}

105 Corresponde a las temporadas 1847 y 1848. 


\begin{tabular}{|c|c|c|c|c|}
\hline Caldas de Oviedo 4 & 43 & 1844,1848 & 1817 & $\begin{array}{l}1858,1860-1863,1865,1866, \\
1868,1871-1876-1898,1898 \\
\text { (quinquenio), } 1899(2), 1900, \\
1901,1909 \text { (quinquenio) }\end{array}$ \\
\hline Marmolejo & 33 & & $1816,1866(3)$ & $\begin{array}{l}1848,1860-1862,1865,1866, \\
1871-1874, \quad 1876-1879,1881- \\
1887,1894-1901\end{array}$ \\
\hline La Aliseda & 9 & 1817 & & 1894-1889, 1901, 1902 \\
\hline Graena & 32 & $\begin{array}{l}1808, \quad 1809, \\
1877\end{array}$ & & $\begin{array}{l}1869,1871,1872,1873 \text { (2), } \\
1877-1890,1892-1901\end{array}$ \\
\hline Alhama de Almería 1 & 13 & $1883(2)$ & & $\begin{array}{l}1878,1880,1881,1882(2), \\
1885,1887-1890,1894,1895\end{array}$ \\
\hline Ardales & 3 & & $1816,1826(2)$ & \\
\hline Bornos & 1 & & 1816 & \\
\hline Caldas de Montbuy 2 & 29 & 1845 & & $\begin{array}{l}1860,1862-1866,1872,1876- \\
1894,1897,1901\end{array}$ \\
\hline Caldetas (Titus) & 25 & 1882,1900 & & $1868,1872,1873,1876-1895$ \\
\hline Alange & 41 & $\begin{array}{ll}1868, & 1895 \\
(2) & \end{array}$ & $\begin{array}{l}1829(6), 1838 \\
(4)\end{array}$ & $\begin{array}{l}1847,1848,185 ?, 1861,1865, \\
1866,1868,1872,1876-1878, \\
1879 \quad(2), 1880-1887,1889- \\
1893,1895-1897,1898 \quad(3), \\
1900,1901\end{array}$ \\
\hline Cortegada & 26 & 1844 & & $\begin{array}{l}1848,1857,1861-1865,1867, \\
1868,1872,1873,1876,1877, \\
1879-1884,1885 \text { (quinquenio), } \\
1885-1888,1903\end{array}$ \\
\hline Caldas de Reyes & 32 & & & 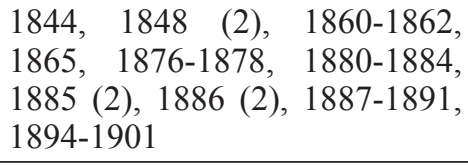 \\
\hline Cuntis & 27 & & & $\begin{array}{l}1844,1848(2), 1860-1866,1868 \\
(3), 1871,1872,1877,1879, \\
1881(3), 1882-1893,1895-1901\end{array}$ \\
\hline Caldelas de Tuy & 44 & $\begin{array}{l}1844, \quad 1866, \\
1892(2)\end{array}$ & $\begin{array}{l}1826, \quad 1829 \\
(2), 1866(9)\end{array}$ & $\begin{array}{lll}1848, & 1858,1860-1863, & 1868, \\
1876 \quad(2), & 1877-1879, & 1882, \\
1884-1886, & 1888-1892, & 1894- \\
1901 & & \\
\end{array}$ \\
\hline Fitero & -36 & & & $\begin{array}{l}\text { (Viejo)1844, 1848, } 1860- \\
1863,1865,1866,1871,1872, \\
1876-1880,1882,1884,1886- \\
1901,1909 \text { (quinquenal, } 1928 \\
\text { (quinquenal) } \\
\text { (Nuevo) } 1848,1860-1866,1868 \\
(3), 1871,1872,1876-1883, \\
1885-1889,1891-1896,1897 \\
(2), 1898-1901\end{array}$ \\
\hline
\end{tabular}




\begin{tabular}{|c|c|c|c|c|}
\hline Belascoain & 15 & & & $\begin{array}{l}1872,1876,1878,1879,1884, \\
1886,1887,1889,1890,1896- \\
1901\end{array}$ \\
\hline Busot & 38 & & $1817,1838(7)$ & $\begin{array}{l}1844,1848,1849,1860-1866, \\
1868,1871-1873, \\
1894,1896,1898\end{array}$ \\
\hline TOTAL & 939 & 38 & 123 & $774(+4)$ \\
\hline
\end{tabular}

Tabla 1. Manuscritos conservados en la Biblioteca de Medicina de la Universidad Complutense de Madrid de los baños que en 1817 debían tener médico director (excepto Fuente del Oro), según la Real resolución de 29 de Abril de 1817 (Gaceta de Madrid, 58 de 15 de mayo de 1817, 502-503). Se indica el año de cada una de las temporadas reflejadas en los manuscritos y entre paréntesis el número de los fechados el mismo año, que sólo en 4 ocasiones son copias.

\section{Referencias bibliográficas}

Abad Varela, M. (1992): “La moneda como ofrenda en los manantiales”, [en] Peréx - Bazzana (coords.), 1992, 133-192 (https://doi.org/10.5944/etfii.5.1992.4189).

Abascal Palazón, J. M. (1990): Inscripciones Romanas de la Provincia de Albacete, Albacete.

Aguado Pintor, A. (2002): "La Isabela, un nuevo Real Sitio para los monarcas del siglo XIX", Espacio, Tiempo y Forma, Historia del Arte 15, 229-254 (https://doi.org/10.5944/ etfvii.15.2002.2400).

Alegre Pérez, M $\mathrm{a}^{\mathrm{a}}$ E. (1984): "Notas sobre algunos abastecimientos de aguas mineromedicinales para uso de las Reales Personas, realizados a través de la Real Botica (s. XIX)", [en] M. Hormigón (coord.), Actas II Congreso de la Sociedad Española de Historia de las Ciencias: Jaca, 27 de Septiembre- 1 de Octubre, 1982, Zaragoza, vol. 2, 5-16.

Andreu Pintado, J. (2018): "La sacralización del agua en Hispania romana: una perspectiva epigráfica”, [en] M J J. Peréx-C. Miró (eds.), Vbi aquae ibi salvs: aguas mineromedicinales, termas curativas y culto a las aguas en la Península Ibérica (desde la Protohistoria a la Tardoantigüedad), Madrid, 91-120.

Arias Ferrer, L. - Matilla Séiquer, G. (2011): "Monedas y balnearios en el Sureste”, [en] J. Torres (coord.), Ars metallica: monedas y medallas: Nules-Valencia, 25-27 de octubre de 2010, Madrid, 713-732.

Ayuda, J. de D. (1793): Examen de las aguas medicinales de mas nombre que hay en las Andalucias: en que se da noticia de la situacion, contenidos, virtudes y metodo con que deben usarse las de cada fuente, vol. I, Baeza.

Batanero Nieto, A. - Alcón García, I. J. (2018): “La excavación arqueológica del Antiguo Establecimiento Carlos III, Balneario Carlos III, Trillo (Guadalajara)", [en] J. M. Faílde F. J. Rodríguez - J. A. Fraiz - M. Gómez - F. Pérez - V. Rodríguez (eds.), Libro de actas del II Symposium Internacional de Termalismo y Calidad de Vida: Ourense (España), 20-21 de septiembre de 2017, Orense, 96-102.

Berbén, A. (1868): Descripcion de los baños minerales de Alanje prov. ${ }^{a}$. de Badajoz para mejor intelig. ${ }^{a}$. de su plano en cumplim. ${ }^{\circ}$. a lo prevenido en el articulo 24 del Reglam. ${ }^{\circ}$. 
orgánico de establtos. de aguas minerales de 11 de marzo de 1868, Facultad de Medicina de la Universidad Complutense de Madrid, Ms. Ca 2794(4).

Broquetas, J. - Broquetas, S. (1790): Luz de la verdad y extinción de preocupaciones, tratado de las aguas thermales de la villa de Caldes de Monbuy del principado de Cataluña, Barcelona.

Cáceres, R. (1829): Descripcion fisico quimico-medica de los baños y aguas minerales de Alange, en la provincia de Extremadura, partido de Merida, precedida de un resumen sobre las aguas en general, consideradas en sus tres estados, solido, liquido, y aeriforme, Facultad de Medicina de la Universidad Complutense de Madrid, Ms. Ca 2861F(13).

Cadenas y Vicent, V. (1984): Jornada de Fernando VII y de Amalia de Sajonia en los Reales Baños de Solán de Cabras en busca del deseado sucesor, Madrid.

Caña y Gamero, A. (1880): Establecimiento balneario de Baños de Molgas en la Provincia de Orense. Memoria correspondiente al año de 1880, Baños de Molgas.

Carmona Barrero, J. D. (2008): "A propósito de una descripción inédita de las termas de Alange en 1829", Revista Almendralejo en Sevilla 15, 43-48.

Cascales Font, J. (1868): Baños termo-minerales de Fortuna [memoria descriptiva], Facultad de Medicina de la Universidad Complutense de Madrid, Ms. Ca 2794(14).

Castillo y Espinosa de los Monteros, J. M. (1845): Memoria sobre las aguas minerales de la villa de Alhama de Murcia, Murcia.

Cisternes y Margarit, J. (1829): Disertacion de las aguas minerales de Villavieja, Alange, Archena, y Caldelas de Tuy, Facultad de Medicina de la Universidad Complutense de Madrid, Ms. Ca 2861F(20).

Colmenero, J. (1697): Tratado maravilloso y utilísimo de las enfermedades que se curan con las salutiferas aguas de los baños de Ledesma, con todas las observaciones que se requieren para el uso de ellas, Salamanca.

Corell Vicent, J. (2008): Inscripcions romanes del País Valencià, IV: Edeta i el seu territori (=Fonts Històriques Valencianes 37), Valencia.

Chinchilla, A.

(1858): Historia natural medica de los baños de Villa-Toya (Sevilla 14 de enero de 1858), Facultad de Medicina de la Universidad Complutense de Madrid, Ms. Ca 2801(10).

(1859): Memoria sobre las aguas y baños mineromedicinales de Villatoya en la provincia de Albacete, Madrid.

Díez de Velasco, F.

(1992): "Aportaciones al estudio de los balnearios romanos de Andalucía: la comarca Guadix-Baza (prov. de Granada)", [en] Peréx - Bazzana (coords.), 1992, 383-400 (https:// doi.org/10.5944/etfii.5.1992.4200).

(1998): Termalismo y religión. La sacralización del agua termal en la Península Ibérica y el norte de África en el mundo antiguo (=Ilu Anejos, Anejo 1), Madrid.

(2014): "La romanidad como reclamo o como omisión: aportaciones al estudio del uso en época romana de los balnearios granadinos de Zújar, Alicún y Graena", Boletín del Centro de Estudios Pedro Suárez 27, 15-44.

Dorado, D. (1776): Compendio histórico de la ciudad de Salamanca, su antigüedad, la de su Santa Iglesia, su fundación y grandezas, Salamanca.

Fabre, C. - Mayer, M. - Rodà, I. (1991): Inscriptions romaines de Catalogne. II, Lérida, Paris (=IRC II).

Fernández López, J.

(1844): Noticias ... sobre el establecimiento de baños y aguas minerales de Busot ..., Facultad de Medicina de la Universidad Complutense de Madrid, Ms. Ca 2858(36). 
(1849): Opúsculos médicos, Alicante.

Fita, F. (1904): "Lápidas romanas de Caldas de Mombuy. Datos inéditos", Boletín de la Real Academia de la Historia 44, 179-190.

García López, A. (2011): El Balneario Real de Carlos III en Trillo (1777-1943), Guadalajara.

García-Talavera Fernández, J. R. (1971): "Historia del cuerpo de médicos de baños: Siglo XIX”, Cuadernos de Historia de la Medicina Española 10, 213-281.

Gómez de Bedoya y Paredes, P.

(1764): Historia universal de las fuentes minerales de España, vol. 1, Santiago de Compostela.

(1765): Historia universal de las fuentes minerales de España, vol. 2, Santiago de Compostela.

Gómez Gabaldon, S. (1822): Disertación sobre las aguas minerales de la villa de Trillo para la oposición de las mismas del año de 1822, Facultad de Medicina de la Universidad Complutense de Madrid, Ms. Ca 2861G(4).

Gómez-Moreno González, M. (1967): Catálogo Monumental de España. Provincia de Salamanca, Valencia.

González Dávila, G. (1606): Historia de las antigüedades de la ciudad de Salamanca: vidas de sus obispos y cosas sucedidas en su tiempo, Salamanca.

González Soutelo, S. - Matilla Séiquer, G. (2017): “Inventario y revisión de los principales enclaves de aguas mineromedicinales en Hispania. Un estado de la cuestión”, [en] Matilla - González-Soutelo (eds.), 2017, 495-602.

Graells, I. (1845): Contestación al interrogatorio de la Comisión nombrada por S. M. para redactar el manual de aguas minerales de España, Facultad de Medicina de la Universidad Complutense de Madrid, Ms. Ca 2858(23).

Guérin-Beauvois, M. - Martin, J.-M. (eds.), (2007): Bains curatifs et bains hygiéniques en Italie de l'antiquité au moyen âge. Actes du colloque réuni à Rome les 22 et 23 mars 2004 (=Collection de l'École française de Rome 383), Rome.

Lara, F. (1973): Epigrafía romana de Lérida, Lérida.

Limón Montero, A. (1697): Espejo cristalino de las aguas de España: hermoseado, y guarnecido, con el Marco de variedad de Fuentes, y Baños, Alcalá.

Lletget y Caylá, T.

(1857): Memoria sobre los baños minerales de Tiermas, Madrid.

(1870): Monografía de los baños y aguas termo-medicinales de Fitero, Barcelona.

López de Ayala, I. (1777): Poema phisico de los Baños Calientes de la villa de Archena en el Reino de Murcia, Murcia.

Maraver Eyzaguirre, F.

(1992): "El termalismo y culto a las aguas en la prensa médica española", [en] Peréx Bazzana (coords.), 1992, 195-210 (https://doi.org/10.5944/etfii.5.1992.4190).

(1997): "Aportaciones de los médicos del cuerpo de baños al termalismo antiguo: Siglo XIX”, [en] Peréx (ed.), 1997, 41-48.

Maraver Eyzaguirre, F. - Armijo Castro, F. (eds.), (2010): Vademécum II de aguas mineromedicinales españolas, Madrid.

Martín de Balmaseda, F. (ed.), (1818): Decretos del rey don Fernando VII: Año cuarto de su restitución al trono de las Españas. Se refieren todas las reales resoluciones generales que se han expedido por los diferentes ministerios y consejos en todo el año de 1817, Madrid.

Martínez Reguera, L. 
(1892): Bibliografía Hidrológico-Médica Española (sección de impresos), Madrid.

(1896): Bibliografía Hidrológico-Médica Española. Segunda parte (Manuscritos y Biografias), vol. 1, Madrid.

(1897): Bibliografía Hidrológico-Médica Española. Segunda parte (Manuscritos y Biografias), vol. 2, Madrid.

Matilla Séiquer, G. (2017): "Balnearios, ciudades y vías. Hacia un planteamiento del problema”, [en] Matilla - González-Soutelo (eds.), 2017, 297-339.

Matilla Séiquer, G. - Egea Vivancos, A. (2015): "El balneario suburbano romano de Fortuna: impacto, tipificación y problemas", [en] J. Ma Álvarez - T. Nogales - I. Rodà (eds.), XVIII Congreso Internacional de Arqueología Clásica. Mérida 2014, Mérida, 883-886.

Matilla Séiquer, G. - Egea Vivancos, A. - Gallardo Carrillo, J. (2003): "El balneario romano de Fortuna. Estado de la cuestión y perspectivas de futuro", Antigüedad y Cristianismo 20, 79-182.

Matilla Séiquer, G. - González-Soutelo, S. (eds.), (2017a): Termalismo Antiguo en Hispania. Un análisis del tejido balneario en época romana y tardorromana en la península ibérica (=Anejos de AEspA 78), Madrid.

Matilla Séiquer, G. - González-Soutelo, S. (2017b): "El balneario romano: Concepto, definición y criterios de jerarquización a partir de los ejemplos hispanos", [en] Matilla González-Soutelo (eds.), 2017, 32-35.

Medel y Cano, J. (1868): Memoria de las aguas minerales sulfo-carbonatadas-alcalinoferreas de Horcajo de Lucena, correspondiente al año de 1868, Facultad de Medicina de la Universidad Complutense de Madrid, Ms. Ca 2795(5).

Medrano Marqués, M. - Díaz Sanz, Ma A. (2005): "Reconstrucción del balneario romano de Fitero (Navarra)", Salduie 5, 177-189.

Méndez Aparicio, J. A.

(2007): "Facultad de Medicina", [en] J. A. Méndez - C. Gállego (coords.), Historia de la biblioteca de la Universidad Complutense de Madrid, Madrid, 322-341.

(2008): Catálogo de Memorias de las aguas minero-medicinales españolas (siglos XIX y XX) existentes en la Biblioteca de la Facultad de Medicina de la Universidad Complutense de Madrid, Madrid.

Mendoza, J. (1829): Disertacion sobre las aguas minerales de Archena, Trillo, Caldelas de Tuy, Alanje y Villavieja, Facultad de Medicina de la Universidad Complutense de Madrid, Ms. Ca $2861 \mathrm{~F}(32)$.

Mezquíriz Irujo, Ma A. (1986): “Las termas romanas de Fitero", [en] Homenaje a José María Lacarra (=Príncipe de Viana, anejo 3), Pamplona, 539-554.

Morales, A. de (1575): Las Antigüedades de las ciudades de España, Alcalá de Henares.

Morandini, F. (2013): "Le acque termali nella Tabula Peutingeriana", [en] M. Bassani - M. Bresan - F. Ghedini (eds.), Aquae salutiferae. Il termalismo fra antico e contemporaneo, Atti del III Convegno Internazionale (Montegrotto Terme, 6-8 settembre 2012), (=Antenor Quaderni 29), Padova, 273-287.

Mostaza, M. (1868): Provincia de Jaen, baños termo-salinos de Jamilena, año de 1868: [descripción del establecimiento], Facultad de Medicina de la Universidad Complutense de Madrid, Ms. Ca 2795(6).

Moya de la Torre y Villarreal, R. - Gutiérrez Bueno, P. (1815): Análisis de las aguas termales de Ledesma, provincia de Salamanca; y apuntamientos sobre el modo de tomar sus baños, defectos que en el se observan y algunos medios de corregirlos: Antigüedad de su uso, enfermedades a que se aplican y tiempo en que se levantó el edificio en que hoy se hallan: Con noticias interesantes a los enfermos que vayan a tomarlos, Facultad de Medicina de 
la Universidad Complutense de Madrid, Ms. Ca 2861F(1).

Oficina de Gaspar y Compañía (ed.), (1815): Coleccion de las reales cedulas decretos y ordenes de su magestad el Señor don Fernando VII desde 1 de enero de 1815, vol. III, Barcelona.

Oró Fernández, E. (1996): “El balneario romano: Aspectos médicos, funcionales y religiosos”, Antigüedad y Cristianismo 13, 23-152.

Palomares, E. (1877): Memoria sobre la naturaleza y virtudes de los manantiales termomedicinales de Zújar, provincia de Granada, Facultad de Medicina de la Universidad Complutense de Madrid, Ms. Ca 2730(4).

Peréx Agorreta, Ma J. (ed.), (1997): Termalismo antiguo. I Congreso Peninsular (La Rioja, 1996), Madrid.

Peréx Agorreta, M ${ }^{\mathrm{a}}$ J. - Bazzana, A. (eds.), (1992): Termalismo antiguo. Aguas mineromedicinales, termas curativas y culto a las aguas en la Península Ibérica, Actas de la mesa redonda (Madrid 1991), (=Espacio Tiempo y Forma, Historia Antigua 5), Madrid (https://doi.org/10.5944/etfii.5.1992).

Peréx Agorreta, Ma J. - Rodríguez Morales, J. (2011): "Las stationes con aquae... en la Tabula de Peutinger", Espacio Tiempo y Forma, Prehistoria y Arqueología 4, 153-170 (https://doi.org/10.5944/etfi.4.2011.10750).

Pérez-Asensio, M. (2017): "Los balnearios del sureste de al-Andalus", [en] Matilla González-Soutelo (eds.), 2017, 407-447.

Pita Cobián, P. (1885): Memoria de las aguas mineromedicinales de Baños de Molgas (provincia de Orense), Pontevedra.

Ponz, A. (1778): Viage de España, en que se da noticia de las cosas mas apreciables, y dignas de saberse, que hay en ella. Tomo IV, Madrid.

Redentor, A. (2017): "Práticas epigráficas e termalismo terapêutico no Noroeste da Hispânia na época romana”, [en] Matilla - González-Soutelo (eds.), 2017, 467-484.

Rodríguez Sánchez, J. A.

(1997): "Historia y legitimación en los tratados hidrológicos españoles del siglo XIX", [en] Peréx (ed.), 1997, 49-58.

(2006): Institucionalización de la Hidrología Médica en España, [en] F. Maraver (coord.), Establecimientos balnearios: historia, literatura y medicina (=Balnea 1), Madrid, 25-40.

Rubio, P. M. (1853): Tratado completo de las fuentes minerales de España, Madrid. 